Full paper

\title{
Earth-abundant transition metal oxides with extraordinary reversible oxygen exchange capacity for efficient thermochemical synthesis of solar fuels
}

\author{
Xiang Gao ${ }^{\mathrm{a}}$, Guanyu Liu ${ }^{\mathrm{a}}$, Ye Zhu ${ }^{\mathrm{b}}$, Peter Kreider ${ }^{\mathrm{c}}$, Alicia Bayon ${ }^{\mathrm{d}}$, Thomas Gengenbach ${ }^{\mathrm{e}}$, Teng Lu , $^{\mathrm{f}}$ \\ Yun Liu ${ }^{\mathrm{f}}$, Jim Hinkley ${ }^{\mathrm{d}}$, Wojciech Lipiński ${ }^{\mathrm{c}, *}$, Antonio Tricoli ${ }^{\mathrm{a}, *}$ \\ ${ }^{a}$ Nanotechnology Research Laboratory, Research School of Engineering, The Australian National University, Canberra, ACT 2601, Australia \\ b Department of Applied Physics, The Hong Kong Polytechnic University, Hung Hom, Kowloon, Hong Kong \\ ${ }^{\mathrm{c}}$ Solar Thermal Group, Research School of Engineering, The Australian National University, Canberra, ACT 2601, Australia \\ d CSIRO Energy, P. O. Box 330, Newcastle, NSW 2300, Australia \\ e CSIRO Manufacturing, Bayview Avenue, Melbourne, VIC 3168, Australia \\ ${ }^{\mathbf{f}}$ Research School of Chemistry, The Australian National University, Canberra, ACT 2601, Australia
}

\section{A R T I C L E I N F O}

\section{Keywords:}

Solar fuels

Transition metal carbides

Redox materials

Oxygen exchange capacity

Earth-abundant transition metals

Thermochemical

\begin{abstract}
A B S T R A C T
Efficient storage of solar and wind power is one of the most challenging tasks still limiting the utilization of the prime but intermittent renewable energy sources. The direct storage of concentrated solar power in renewable fuels via thermochemical splitting of water and carbon dioxide on a redox material is a scalable approach with up to $54 \%$ solar-to-fuel conversion efficiency. Despite progress, the search for earth-abundant materials that can provide and maintain high $\mathrm{H}_{2}$ and $\mathrm{CO}$ production rates over long period of high-temperature cycles continues. Here, we report a strategy to unlock the use of manganese, the 12th most abundant element in the Earth's crust, for thermochemical synthesis of solar fuels, achieving superior thermochemical stability, oxygen exchange capacity, and up to seven times higher mass-specific $\mathrm{H}_{2}$ and $\mathrm{CO}$ yield than cerium dioxide. We observe that incorporation of a small fraction of cerium ions in the manganese (II,III) oxide crystal lattice drastically increases its oxygen ion mobility, allowing its reduction from oxide to carbide during methane partial oxidation with simultaneous Ce exsolution. High $\mathrm{CO}_{2}$ and $\mathrm{H}_{2} \mathrm{O}$ splitting rates are achieved by re-oxidation of the carbide to manganese (II) oxide with simultaneous reincorporation of the cerium ions. We demonstrate that the oxide to carbide reaction is highly reversible achieving remarkable $\mathrm{CO}_{2}$ splitting rates over 100 thermochemical cycles of methane partial oxidation and $\mathrm{CO}_{2}$ splitting, and preserving the initial oxygen exchange capacity of $0.65 \mathrm{~mol}_{\mathrm{O}}$ $\mathrm{mol}_{\mathrm{Mn}}^{-1}$ and $89 \%$ of the fuel production rates. Due to this extraordinarily high reversible oxygen exchange capacity, the $3 \%$ Ce-doped manganese oxide achieves an average mass-specific $\mathrm{CO}$ yield for $\mathrm{CO}_{2}$ splitting of $17.72 \mathrm{mmol}_{\mathrm{CO}} \mathrm{g}^{-1}$, which is significantly higher than that previously achieved in thermochemical redox cycles. More generally, these findings suggest that incorporation of small soluble amounts of cerium in earth-abundant transition metal oxides like manganese oxide is a powerful approach to enable solar thermochemical fuel synthesis.
\end{abstract}

\section{Introduction}

Reduction of anthropogenic carbon emissions is a pivotal task requiring significant progress in renewable energy conversion and storage technologies. Direct synthesis of renewable fuels via solar thermochemical splitting of water and carbon dioxide can enable the use of this prime renewable energy source for transport, off-the-grid power generation and storage as well as production of numerous commodities. Extensive efforts have been devoted to find efficient processes that can reduce the excessively high temperatures $(>3300 \mathrm{~K}$ ) required for direct thermal dissociation of $\mathrm{CO}_{2}$ and $\mathrm{H}_{2} \mathrm{O}$ into $\mathrm{CO}, \mathrm{H}_{2}$ and $\mathrm{O}_{2}$, and facilitate the separation of these gases $[1,2]$. Two-step reduction-oxidation (redox) cycles using a metal oxide as an intermediate oxygen exchange material are one of the most promising processes for largescale water and carbon dioxide splitting [2-4]. Recently, it was shown that by promoting the reduction of the metal oxide material with methane partial oxidation (MPO) rather than by inert gas sweeping (IGS), it is possible to decrease the required reaction temperature from $1600 \mathrm{~K}$

\footnotetext{
* Corresponding authors.

E-mail addresses: wojciech.lipinski@anu.edu.au (W. Lipiński), antonio.tricoli@anu.edu.au (A. Tricoli).
} 
to less than $1200 \mathrm{~K}[5-7,64]$. This MPO-driven metal oxide reduction also increases the solar-to-fuel conversion efficiency limit from $19 \%$ for the IGS-driven cycles to 54\% [1,7-9]. Notably, the resulting $\mathrm{CO}$ and $\mathrm{H}_{2}$ products can be adjusted to match the required composition ratio for production and downstream processing of syngas, providing a simple pathway for large-scale synthesis of liquid fuels via established industrial solutions such as the Fischer-Tropsch process.

A major challenge of solar thermochemical redox cycles is the search for earth-abundant low-cost materials that can provide high oxygen exchange capacity and fast fuel production rates over thousands of high temperature cycles in harsh environmental conditions. Many binary, ternary, and complex oxides such as ferries and perovskites have been explored, with the highest performing materials including $\mathrm{CeO}_{2}$ [10-12], $\mathrm{Ce}_{x} \mathrm{Zr}_{1-x} \mathrm{O}_{2}$ [13], $\mathrm{FeAl}_{2} \mathrm{O}_{4}$ [14] and $\mathrm{La}_{x} \mathrm{Sr}_{1-x} \mathrm{Mn}_{y} \mathrm{Al}_{1-y} \mathrm{O}_{3}$ [15-17]. Nanostructured cerium dioxide $\left(\mathrm{CeO}_{2}\right)$ remains the benchmark material for thermochemical cycles, featuring high mass-specific production rates of $\mathrm{H}_{2}$ and $\mathrm{CO}$ [12]. Despite the fast reaction kinetics, $\mathrm{CeO}_{2}$ provides only low oxygen exchange capacities of below $0.25 \mathrm{~mol}_{\mathrm{O}}$ $\operatorname{mol}_{\mathrm{Ce}}^{-1}[7,12]$, while maintaining its cubic fluorite crystal structure. Additionally, $\mathrm{CeO}_{2}$ has been reported to suffer from a decline in production rates, due to loss of surface area after the initial cycles at moderate temperatures (1173 K) $[1,12,18,19]$. Enhancement of the initial oxygen exchange capacity and morphological stability by using support materials such as $\mathrm{MgO}$ has resulted in a maximum of only $0.43 \mathrm{~mol}_{\mathrm{O}} \mathrm{mol}_{\mathrm{Ce}}^{-1}$ at $1273 \mathrm{~K}$. Since the oxygen exchange capacity provides the upper limit for the fuel production of each cycle, it is critical to develop materials that provide and maintain higher oxygen exchange capacity than $\mathrm{CeO}_{2}$ in harsh thermochemical environments. In addition, cerium is a rare earth element, and while it is the most abundant of the lanthanides with a content in the Earth's crust of around $70 \mathrm{ppm}$, its extraction from natural deposits is laborious posing limitations for its future use in such large-scale energy conversion processes [20].

In search of higher oxygen exchange capacities and more earthabundant cations, numerous transition metals have been explored as alternative to cerium, including $\mathrm{BaMn}_{x} \mathrm{Fe}_{1-x} \mathrm{O}_{3}$ [15], $\mathrm{Ni}_{x} \mathrm{Fe}_{3-x} \mathrm{O}_{4}$ [21], and $\mathrm{La}_{x} \mathrm{Sr}_{1-x} \mathrm{MnO}_{3}$ [16]. Notwithstanding their extraordinary abundancy, iron-based metal oxides suffer from even faster deactivation than $\mathrm{CeO}_{2}$ [15,22]. As an alternative, manganese is the 12th most abundant element in the Earth's crust with a concentration of $1000 \mathrm{ppm}$, and its oxides can be readily obtained by refining low-cost minerals such as pyrolusite and hausmannite [23-25]. Small fractions of manganese ions have been incorporated into benchmark metal oxides, such as $\mathrm{CeO}_{2}$ [26] and perovskites [17], demonstrating improved oxygen exchange capacity and overall $\mathrm{H}_{2}$ yield in thermochemical water splitting [26]. However, there are currently no studies reporting the direct use of manganese oxide for thermochemical water or $\mathrm{CO}_{2}$ splitting, due to thermodynamic limitations. An indirect threestep cycle for $\mathrm{H}_{2}$ generation was demonstrated by utilizing $\mathrm{MnO}$ and $\mathrm{NaOH}$, subsequent hydrolysis of the birnessite mineral phase to generate $\mathrm{Mn}_{2} \mathrm{O}_{3}$ and regenerate $\mathrm{NaOH}$, followed by high-temperature reduction of $\mathrm{Mn}_{2} \mathrm{O}_{3}$ to $\mathrm{MnO}$ [27-31]. The latter approach suffers from energy losses due to the significant temperature swings (ca. $750 \mathrm{~K}$ ) between the reduction and the hydrolysis steps, and incomplete recovery of sodium during hydrolysis.

Here, we present a strategy to enhance the reaction rates and drastically increase the oxygen exchange capacity of manganese oxide, unlocking its use for efficient direct synthesis of solar fuels. We have observed that the incorporation of soluble amount of cerium ions in manganese oxide enables its reduction to manganese carbide with an extraordinary theoretical oxygen exchange capacity of one mole of oxygen per mole of manganese. Thereafter, the significant oxidation enthalpy of the carbide can be utilized to drive the carbon dioxide and water splitting reactions with unprecedentedly high $\mathrm{CO}$ and $\mathrm{H}_{2}$ yields. We hypothesise that incorporation of the cerium ions drastically increases the oxygen ion mobility in the manganese oxide lattice enabling the thermodynamically favourable formation of an intermediate transition metal carbide, and its re-oxidation during water and carbon dioxide splitting. Importantly, while the cerium exsolutes during the reduction step, it is fully reincorporated during the oxidation step allowing long-term cyclability. We demonstrate the potential of this material by the production of valuable syngas, a mixture of $\mathrm{CO}$ and $\mathrm{H}_{2}$, at record-high yields over $100 \mathrm{CO}_{2}$ splitting cycles with harsh methanedriven reduction steps. We believe that these findings may be applied to many members of the large family of earth-abundant transition metals setting the basis to overcome one of the longstanding challenges for the efficient thermochemical synthesis of solar fuels.

\section{Experimental}

\subsection{Synthesis of nanostructures}

The ultra-fine pure $\mathrm{Mn}_{3} \mathrm{O}_{4}$ and $3 \%$ (atomic) Ce-doped $\mathrm{Mn}_{3} \mathrm{O}_{4}(3 \%$ Ce $\mathrm{Mn}_{3} \mathrm{O}_{4}$ ) nanoparticles were synthesised using a custom built flame spray pyrolysis setup $[12,32,33]$. The precursor liquid solution for synthesising pure $\mathrm{Mn}_{3} \mathrm{O}_{4}$ was prepared by dissolving manganese (III) acetylacetonate (Sigma Aldrich, technical grade) in 2-ethylhexanoic acid (Sigma Aldrich, purity $\geq 99 \%$ ) with a total atomic concentration of $\mathrm{Mn}$ ions at $0.4 \mathrm{~mol} \mathrm{~L}^{-1}$. Similarly, the precursor solution for synthesising 3\% Ce $\mathrm{Mn}_{3} \mathrm{O}_{4}$ was prepared by mixing cerium (III) acetate hydrate (Sigma Aldrich, purity 99.9\%) with manganese acetylacetonate at a Ce:Mn atomic ratio of 3:97, and dissolving the mixture in 2ethylhexanoic acid with a total atomic concentration of the metal ions at $0.4 \mathrm{~mol} \mathrm{~L}^{-1}$. Both solutions were heated in $368 \mathrm{~K}$ oil bath and subsequently added with equal volumetric amount of xylene to reach a total metal ion concentration of $0.2 \mathrm{~mol} \mathrm{~L}^{-1}$. The final combustible solutions were fed at $5 \mathrm{~mL} \mathrm{~min}{ }^{-1}$ rate through a custom-built nozzle, and atomised with an oxygen flow of 5 SLPM (grade 4.0) with a pressure drop of ca. 4 bar. The resulting spray was ignited with a surrounding annular premixed methane (flow rate of 1.2 SLPM, grade 4.5) and oxygen (flow rate of 2 SLPM, grade 4.0) flame. Nanoparticle powders were collected with a vacuum pump (ICME Type M80B4) on water-cooled glass-fibre filters (Sartorius glass microfiber, $150 \mathrm{~mm}$ diameter) placed at ca. $40 \mathrm{~cm}$ height above the burner.

\subsection{Setup for methane partial oxidation and $\mathrm{CO}_{2}$ splitting cycles}

The cyclic MPO and $\mathrm{CO}_{2}$ splitting performance of pure $\mathrm{Mn}_{3} \mathrm{O}_{4}$ and $3 \% \mathrm{Ce} \mathrm{Mn}_{3} \mathrm{O}_{4}$ is investigated in a vertical-tube reactor placed inside an infrared gold image furnace(P4C-VHT, Advance Riko) illustrated in a previous work [12]. The powder samples are packed between two pieces of $2 \mathrm{~mm}$ thick highly porous and temperature-resistant aluminabased fibres (ALBF-1, 97\% $\mathrm{Al}_{2} \mathrm{O}_{3}$ and $3 \% \mathrm{SiO}_{2}$, ZIRCAR), located onaxis of the vertical alumina tube to allow for a nearly uniform mass flow distribution on the gas-solid interface. All the samples have a mass of $200 \pm 2 \mathrm{mg}$, resulting in a powder layer thickness of $1-2 \mathrm{~mm}$. The mass of the samples and the packing fibres were measured before and after the redox cycles. No apparent mass loss was observed except up to $7 \%$ mass change of the samples induced by the cycle chemistry. Increasing the sample mass to $300 \mathrm{mg}$ and $500 \mathrm{mg}$ resulted in lower material activity, due to mass transfer-limited reactions during the redox cycles. Gas flow rates are regulated by mass flow controllers (F$201 \mathrm{CV}$, Bronkhorst) before being delivered through the top of the tube. Sample temperature is measured using an alumina sealed type-K thermocouple located directly under the packed samples. The composition of the product gases is continuously monitored by a quadrupole mass spectrometer (OmniStar ${ }^{\mathrm{TM}}$ GSD 320, Pfeiffer Vacuum). All gas volumes are reported at SATP conditions (298 K, 1 bar).

To find the effective redox stoichiometry of the materials, the tubular reactor was initially purged of air under a flow of pure Ar (grade 5.0) at room temperature. The reactor was then heated from ambient room temperature to the optimised isothermal operating temperature of $1173 \mathrm{~K}$ at a ramp of $80 \mathrm{Kmin}^{-1}$. Subsequently, the sample was 
cyclically reduced by $\mathrm{CH}_{4}$ (grade 4.5) and oxidized by $\mathrm{CO}_{2}$ (grade 4.5). The reduction step was performed using a mixture of $\mathrm{CH}_{4}$ in $\mathrm{Ar}$ (8 vol\%) at a total flow rate of $250 \mathrm{~mL} \mathrm{~min}^{-1}$ for $90 \mathrm{~min}$. Then the tube was purged with $\mathrm{Ar}\left(250 \mathrm{~mL} \mathrm{~min}^{-1}\right)$ for $10 \mathrm{~min}$. The oxidation step was initiated by delivering a mixture of $\mathrm{CO}_{2}$ in $\mathrm{Ar}(4 \mathrm{vol} \%$ ) at a total flow rate of $250 \mathrm{~mL} \mathrm{~min}^{-1}$ for $75 \mathrm{~min}$. The tube was again purged with Ar $\left(250 \mathrm{~mL} \mathrm{~min}^{-1}\right.$ ) for $10 \mathrm{~min}$ before the next cycle began. The time set for the reduction steps was determined from preliminary tests by monitoring the instantaneous $\mathrm{H}_{2}$ : $\mathrm{CO}$ evolution ratios. As the deviation of the $\mathrm{H}_{2}$ : $\mathrm{CO}$ ratios caused by thermal cracking of $\mathrm{CH}_{4}$ begins to dominate after ca. $120 \mathrm{~min}$ into the reduction step, it will compromise the credibility of the desirable products produced via the major redox reactions. Therefore, the full reduction of the samples was not investigated in this study. The subsequent oxidation steps were kept sufficiently long enough to reoxidize as much of the samples as possible. For $\mathrm{H}_{2} \mathrm{O}$ splitting, steam vapour was generated from a bubbler filled with DI water and kept at the targeted temperature selected between 348 and $378 \mathrm{~K}$. An Ar gas flow at $20 \mathrm{~mL} \mathrm{~min}^{-1}$ passed through the bubbler and was further diluted with $230 \mathrm{~mL} \mathrm{~min}^{-1}$ of Ar before delivering steam vapour into the reactor tube.

To demonstrate the intermediate cyclic stability of $3 \% \mathrm{Ce} \mathrm{Mn}_{3} \mathrm{O}_{4}$, a 100 -cycle $1173 \mathrm{~K}$ isothermal test with $6 \mathrm{~min}$ for reduction and $12 \mathrm{~min}$ for oxidation using the same input gas flow composition as above was performed. The Ar purge gas was increased to $500 \mathrm{~mL} \mathrm{~min}^{-1}$ and kept for $5 \mathrm{~min}$ after each reduction and oxidation step. Automated gas switch and flow rate control was operated using an in-house developed LabVIEW (National InstrumentsTM) application integrated with the mass flow controllers and pneumatically actuated valves (1315R, Swagelok). As a comparative study, commercial $\mathrm{CeO}_{2}$ powders (Alfa Aesar, purity $99.995 \%$ ) was also tested for 100 cycles with the same conditions.

\subsection{Sample characterization}

Samples were characterised before and after the cyclic MPO and $\mathrm{CO}_{2}$ splitting tests. X-ray diffraction (XRD) was performed using a D2 phaser diffractometer (Bruker). Each sample powder was scanned using $\mathrm{Cu} \mathrm{K \alpha}(1.54 \AA)$ radiation source with an operating voltage of $30 \mathrm{kV}$ and a current of $10 \mathrm{~mA}$. The scanning rate of $0.75^{\circ} \mathrm{min}^{-1}$ was applied to record the XRD patterns in the $2 \theta$ range of $10-80^{\circ}$ at an increment of $0.02^{\circ}$. The Scherrer equation was applied for the most intense peaks to determine the crystalline domain size. The quantitative analysis was performed based on parabolic fitting using pseudo-Voigt profile parameters.

Information of the particle morphology and lattice plane spacing was analysed using a high-resolution transmission electron microscope (HR-TEM, JEOL 2100F) operated at $200 \mathrm{kV}$. Samples were deposited on 200-mesh carbon-filmed copper grids for imaging. Primary particle size and lattice plane spacing were obtained via the image processing software ImageJ. Additional energy dispersive X-ray spectroscopy (EDX) was performed using the scanning transmission electron microscopy (STEM) mode on the JEOL 2100F. Elemental mapping was carried out by scanning a STEM probe over the area of interest and acquiring EDX spectra at every beam positions. Atomic resolution STEM imaging and electron energy loss spectroscopy (EELS) was carried out on an aberration-corrected FEI Titan STEM operated at $300 \mathrm{kV}$.

X-ray photoelectron spectroscopy (XPS) analysis was performed using an AXIS Nova spectrometer (Kratos Analytical Inc., Manchester, UK) with a monochromatic $\mathrm{Al} \mathrm{Ka}$ source at a power of $180 \mathrm{~W}$ $(15 \mathrm{kV} \times 12 \mathrm{~mA})$ with a hemispherical analyser operating in the fixed analyser transmission mode and the standard aperture (analysis area: $0.3 \mathrm{~mm} \times 0.7 \mathrm{~mm}$ ). The total pressure in the main vacuum chamber during analysis was typically around $10^{-8}$ mbar. Samples were loaded into shallow wells of custom-built sample holders. One batch of each sample was prepared. Two different locations were analysed on each sample at a nominal photoelectron emission angle of $0^{\circ}$ with respect to the surface normal. As the actual emission angle is ill-defined in the case of powders (ranging from $0^{\circ}$ to $90^{\circ}$ ), the sampling depth may range from $0 \mathrm{~nm}$ to ca. $10 \mathrm{~nm}$. Survey spectra were acquired at pass energy of $160 \mathrm{eV}$. To obtain more detailed information about chemical structure and oxidation states, high resolution spectra were recorded from individual peaks at $40 \mathrm{eV}$ pass energy. Data processing was performed using CasaXPS processing software version 2.3.15 (Casa Software Ltd., Teignmouth, UK). All elements present were identified from survey spectra. Binding energies were referenced to the C 1 s peak at $284.8 \mathrm{eV}$ for aliphatic hydrocarbon.

The carbon content of the samples formed after the reduction and oxidation was evaluated by TG-DSC analysis in a STA8000 Simultaneous Thermal Analyser (PerkinElmer). Samples were calcined in air $\left(100 \mathrm{~mL} \mathrm{~min}^{-1}\right)$ in the temperature range of $303-1273 \mathrm{~K}$ at $5 \mathrm{~K} \mathrm{~min}^{-1}$. Evolution of sample mass and heat flow were recorded.

The BET specific surface area was measured by $\mathrm{N}_{2}$ adsorption-desorption isotherms at $77 \mathrm{~K}$, using a surface and porosity analyser (TriStar II, Micromeritics), upon $4 \mathrm{~h}$ degassing at $423 \mathrm{~K}$.

\subsection{Reaction equilibrium and thermodynamic analysis}

The proposed reactions and the equilibriums were evaluated using the FactSage thermochemical analysis software [34]. The databases used in the calculations include FACT pure substances (FactPS), oxides (FToxid, including solid solution phases [35]) and miscellaneous (FTmisc) databases. The Gibbs free energy change $(\Delta \mathrm{G})$ of each reaction as a function of the equilibrium temperature were calculated between $473 \mathrm{~K}$ and $1573 \mathrm{~K}$. All $\Delta \mathrm{G}$ values were normalised as per unit mol of Mn in each equation. To obtain the equilibrium composition as a function of the temperature, the initial products were set as the stoichiometric molar amount according to the reaction equations shown in Fig. A2. All gases were treated as ideal gases under 1 bar.

\section{Results and discussion}

To investigate the feasibility of doping the manganese oxide crystal lattice with cerium ions, composite nanoparticles with Ce concentration varying from $3 \%$ to $50 \%$ of the total metal atom content were synthesised by flame spray pyrolysis. The synthesis method was chosen as a scalable method capable of synthesising high purity manganese oxide nanocrystals with well-controlled structural properties in one step [24]. All of the as-prepared nanocomposites consisted of $\mathrm{Mn}_{3} \mathrm{O}_{4}$ crystals with a mixed $\mathrm{Mn}$ (II) and $\mathrm{Mn}$ (III) oxidation state (Fig. A1). Incorporation of up to $10 \%$ of Ce resulted in a solid solution with the $\mathrm{Mn}_{3} \mathrm{O}_{4}$ matrix, while further increasing the Ce content resulted in its segregation and formation of a separated $\mathrm{CeO}_{2}$ crystal phase. Upon initial trials, it was found that the $3 \%$ Ce provided an optimal enhancement of the reduction and oxidation kinetics of the manganese oxide. This optimal composition was further comparatively investigated with the pure manganese oxide, and benchmarked against $\mathrm{CeO}_{2}$.

Fig. 1 shows a structural comparison of the as-prepared pure and $3 \%$ Ce $\mathrm{Mn}_{3} \mathrm{O}_{4}$ nanoparticles. Both materials show similar nanoscale morphology consisting of agglomerated quasi-spherical primary particles with an average diameter of $11.2 \mathrm{~nm}$ and a geometric standard deviation of 1.7 (Fig. A3). High-resolution transmission electron microscopic (HR-TEM) analysis of these samples reveals similar hexagonally-shaped monocrystalline nanoparticles and exposed (101) facets for both materials (Fig. 1a, b). However, while the fringe spacing of the pure $\mathrm{Mn}_{3} \mathrm{O}_{4}$ (Fig. 1a, inset) matches well the $0.49 \mathrm{~nm}$ lattice spacing of the (101) $\mathrm{Mn}_{3} \mathrm{O}_{4}$ plane $[24,36]$, the $3 \%$ Ce one is broader $(0.51 \mathrm{~nm})$ suggesting a distortion of the tetragonal hausmannite crystal structure (Fig. 1b, inset). These results were further corroborated by X-ray diffraction (XRD) analysis (Fig. 1c), which confirms the same $\mathrm{Mn}_{3} \mathrm{O}_{4}$ phase (JCPDS no. 24-0734) and average crystallite size of approx. $11 \mathrm{~nm}$ for both pure

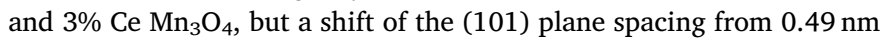
of the former to $0.51 \mathrm{~nm}$ of the latter. The successful incorporation of 

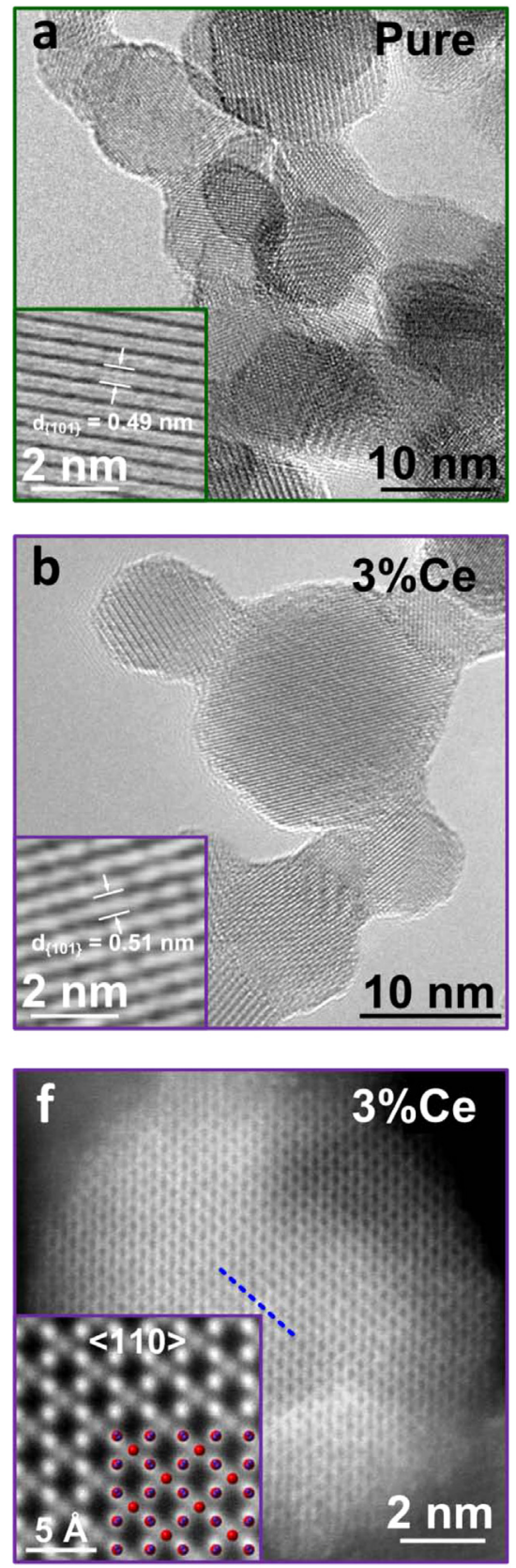
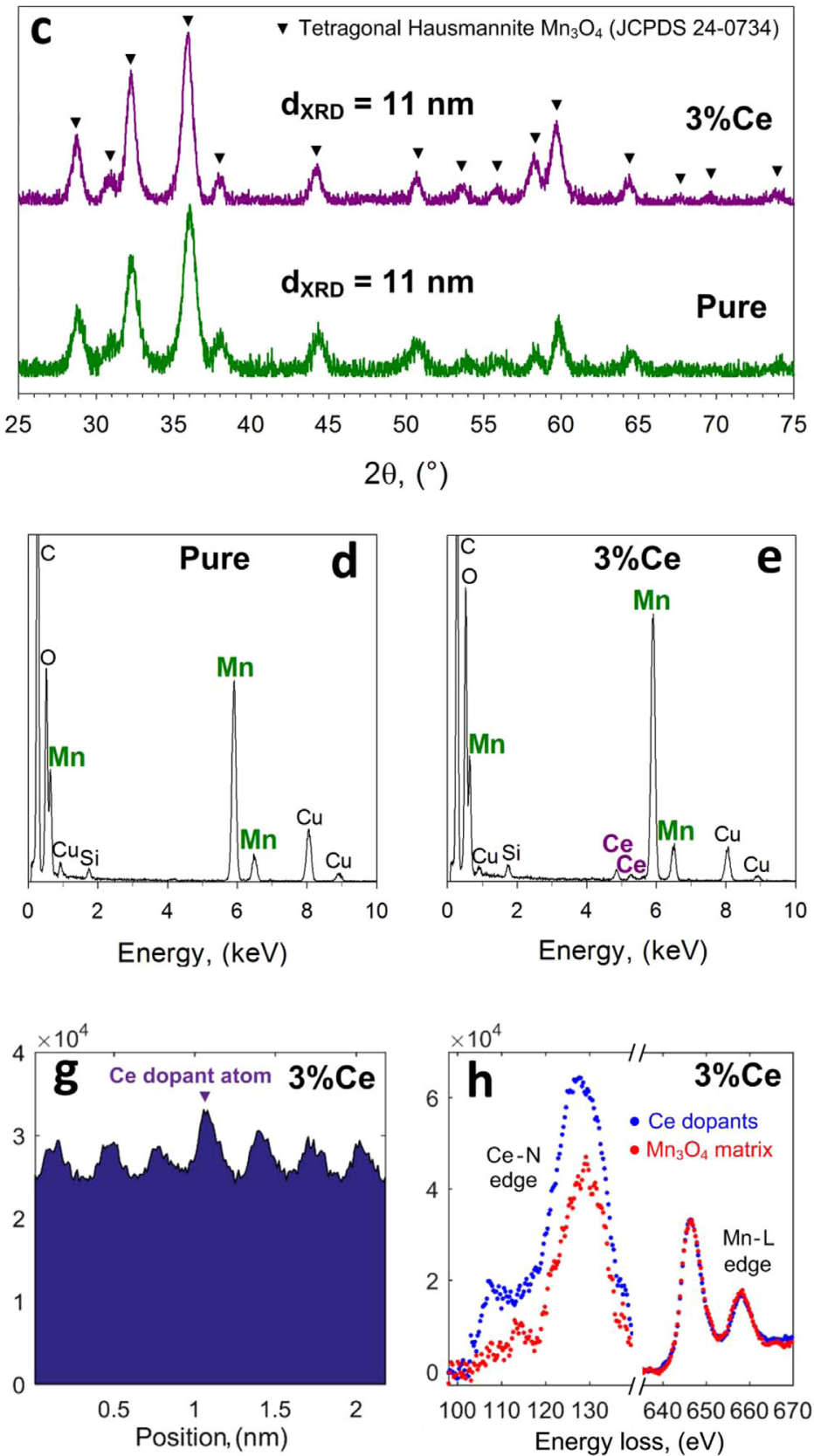

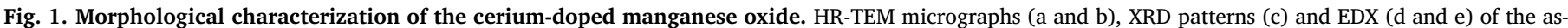

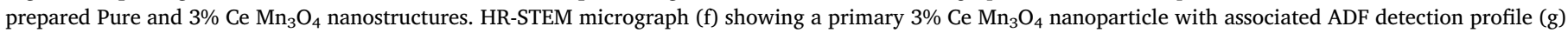
and EELS (h) along the dotted line.

the cerium ions was confirmed by energy-dispersive X-ray spectroscopy (EDX) analysis (Fig. 1e), showing characteristic Ce emission energies, in

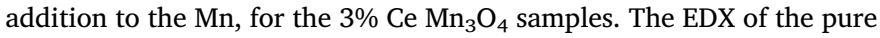
manganese oxide reveals only $\mathrm{Mn}$, and the presence of carbon and copper from the TEM grid (Fig. 1d). The increase in lattice spacing, observed in the Ce-doped samples, is tentatively attributed to the incorporation of the cerium ions that have larger ionic radii $\left(\mathrm{Ce}^{4+}\right.$ : $\left.0.097 \mathrm{~nm} ; \mathrm{Ce}^{3+}: 0.114 \mathrm{~nm}\right)$ than manganese $\left(\mathrm{Mn}^{4+}: 0.053 \mathrm{~nm} ; \mathrm{Mn}^{3+}\right.$ : $0.065 \mathrm{~nm} ; \mathrm{Mn}^{2+}: 0.083 \mathrm{~nm}$ ) [37]. The surface potentials of pure $\mathrm{Mn}_{3} \mathrm{O}_{4}$ and $3 \% \mathrm{Ce} \mathrm{Mn}_{3} \mathrm{O}_{4}$ was further investigated by Kelvin probe force microscopy and presented no significant contact potential difference (ca. $50 \mathrm{mV}$ ) (Fig. A8), suggesting a similar surface affinity to reaction products.

The atomic distribution of the cerium ions was further investigated by annular dark-field imaging (ADF) and electron energy loss spectroscopy (EELS) analysis across the (110) plane of the Ce-doped samples. Fig. 1f shows a high-resolution scanning transmission electron microscopic (HR-STEM) image of a monocrystalline 3\% Ce $\mathrm{Mn}_{3} \mathrm{O}_{4}$ particle and a high-magnification (inset) of the lattice image matching well the $\mathrm{Mn}_{3} \mathrm{O}_{4}$ structure model at the $<110>$ zone axis [24]. EELS line scanning (Fig. 1h) and its associated ADF detection profile (Fig. 1g) show localized and increased intensities, which are associated with the presence of the Ce dopants and further confirm the formation of a substitutional $\left(\mathrm{Mn}_{0.97} \mathrm{Ce}_{0.03}\right)_{3} \mathrm{O}_{4}$ solid solution with no detectable segregation or clustering of the Ce inside the grains. The oxidation state of the cerium ions and possible variation in the electronic structure of the Mn were investigated by X-ray photoelectron spectroscopy (Fig. 2). The

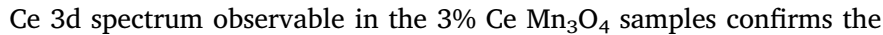
presence of tetravalent cerium (Fig. 2a). In particular, the $\mathrm{Ce}^{4+}$ oxidation state is associated with a dominant peak at $917.0 \mathrm{eV}$ [38]. The 

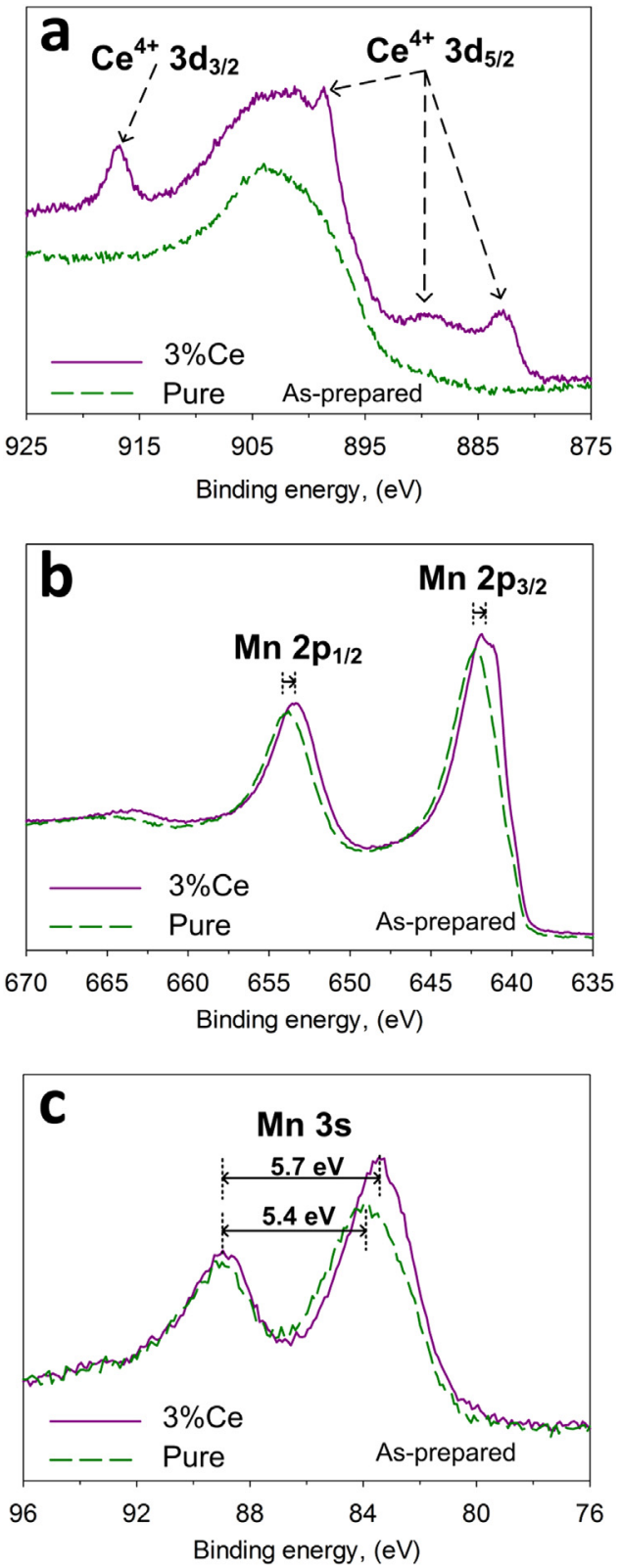

Fig. 2. Structural characterization of the cerium-doped manganese oxide. XPS of the as-prepared Pure and $3 \% \mathrm{Ce} \mathrm{Mn}_{3} \mathrm{O}_{4}$ showing the characteristic spectra of (a) Ce 3d, (b) Mn 2p and (c) Mn 3s.

same spectrum with the broad Mn LMM Auger peak subtracted in the same spectral region (875-925 eV binding energy) to present the pure Ce $3 \mathrm{~d}$ spectrum is shown in Fig. A5. The Ce ${ }^{4+}$ presence in the $\mathrm{Mn}_{3} \mathrm{O}_{4}$ lattice appears to decrease the oxidation state of the manganese cations; this partial reduction of $\mathrm{Mn}$ is evidenced by a stronger intensity contribution to the Mn 2p spectrum at lower binding energy $(641 \mathrm{eV}$; Fig. 2b), and an increased multiplet splitting of the Mn 3s doublet (Fig. 2c) [39]. It is hypothesised that the cerium ions may act as electron donor weakening the Mn-O bonds.

To investigate the overall impact of these structural reorganization on the oxygen exchange capacity and redox kinetics of the manganese oxide matrix, four sequential reduction and oxidation cycles were conducted comparatively with the pure and $3 \%$ doped manganese oxide (Fig. 3a, b). To increase the overall thermal energy-to-fuel efficiency limit and decrease the required reaction temperature, methane partial oxidation was utilized in the reduction step. A temperature of $1173 \mathrm{~K}$ was chosen as close to the lowest $(1150 \mathrm{~K})$ possible for the
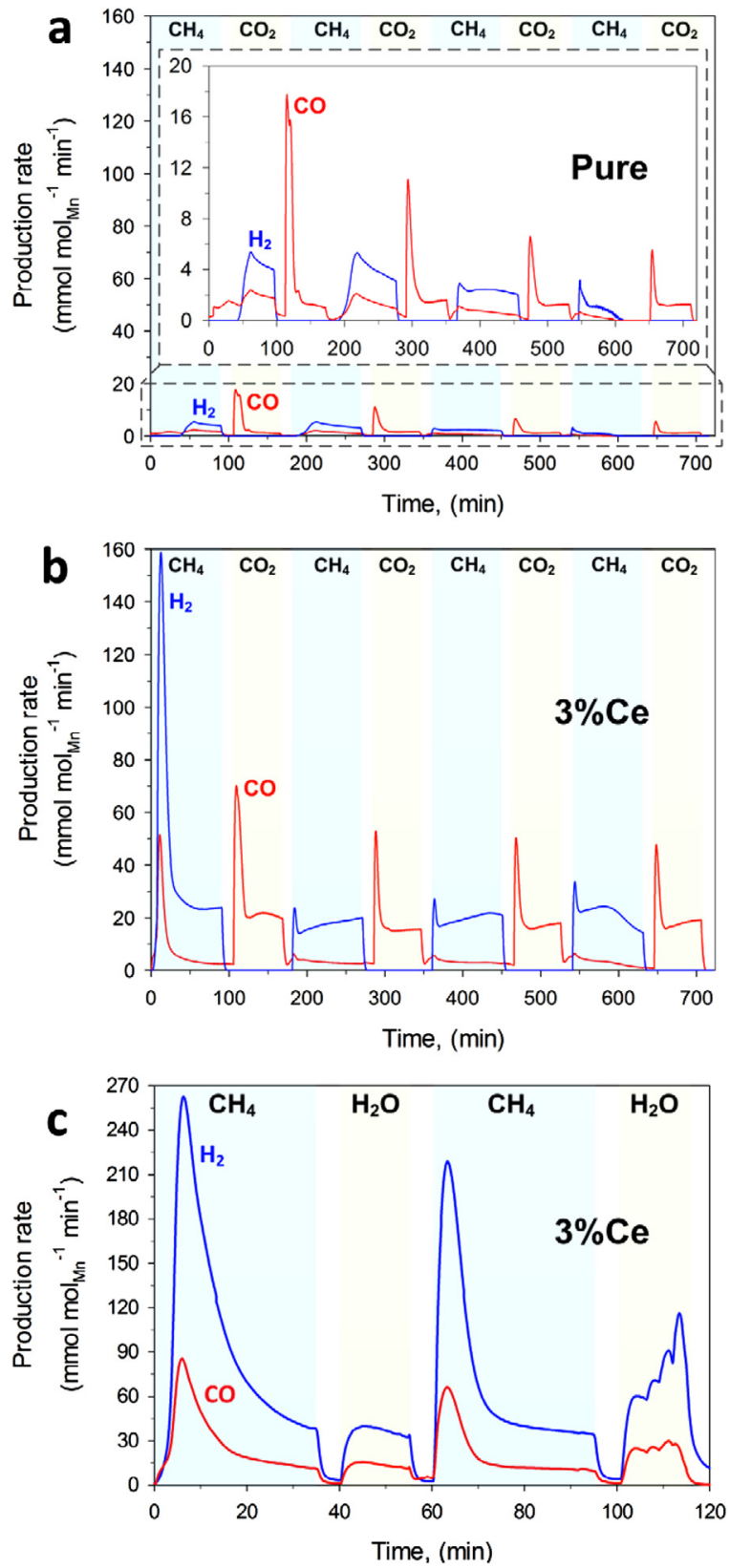

Fig. 3. Efficient carbon dioxide splitting via the oxide-carbide cycle. $\mathrm{H}_{2}$ and $\mathrm{CO}$ production rates of the (a) Pure and (b) $3 \%$ Ce $\mathrm{Mn}_{3} \mathrm{O}_{4}$ during 4 isothermal cycles of methane partial oxidation and $\mathrm{CO}_{2}$ splitting at $1173 \mathrm{~K}$. (c) $\mathrm{H}_{2}$

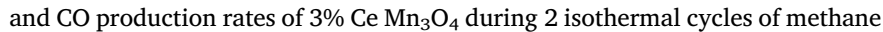
partial oxidation and $\mathrm{H}_{2} \mathrm{O}$ splitting at $1173 \mathrm{~K}$.

thermodynamically favourable partial oxidation of methane with small amount of $\mathrm{CH}_{4}$ cracking and carbon formation (Fig. A2a, c). Furthermore, this is also a suitable temperature to activate the subsequent exothermic oxidation step allowing the execution of the whole two-step cycle isothermally [40-42]. This decreases thermal losses that are associated with the temperature swings, required with inert gas reduction steps [14]. The re-oxidation kinetics was investigated in detail for $\mathrm{CO}_{2}$ splitting (Fig. 3a, b), and further validated also for $\mathrm{H}_{2} \mathrm{O}$ splitting (Fig. 3c). The overall thermodynamic reaction stoichiometry for this redox cycle (Fig. A2) indicates favourable formation of manganese carbide $\left(\mathrm{Mn}_{7} \mathrm{C}_{3}\right)$ by methane partial oxidation in the first step (Eqs. (1), (2)), and complete re-oxidation to manganese (II) oxide by $\mathrm{CO}_{2}$ splitting during the second step (Eq. (3)) [43-45]: 
Table 1

Syngas yields and CO selectivity between pure $\mathrm{Mn}_{3} \mathrm{O}_{4}$ and $3 \%$ Ce $\mathrm{Mn}_{3} \mathrm{O}_{4}$ over 4 cycles of methane partial oxidation and CO $\mathrm{C}_{2}$ splitting.

\begin{tabular}{|c|c|c|c|c|c|c|}
\hline \multirow[t]{2}{*}{ Material } & \multirow[t]{2}{*}{ Cycle } & \multicolumn{4}{|l|}{ Reduction (MPO) } & \multirow{2}{*}{$\begin{array}{l}\text { Oxidation (CDS) } \\
\mathrm{CO} \text { yield ( } \mathrm{mol} \mathrm{mol}_{\mathrm{Mn}}^{-1} \text { ) }\end{array}$} \\
\hline & & $\mathrm{H}_{2}$ yield $\left(\mathrm{mol} \mathrm{mol}_{\mathrm{Mn}}^{-1}\right)$ & $\mathrm{CO}$ yield $\left(\mathrm{mol} \mathrm{mol}_{\mathrm{Mn}}^{-1}\right)$ & $\mathrm{CO}_{2}$ yield $\left(\mathrm{mol} \mathrm{mol}_{\mathrm{Mn}}^{-1}\right)$ & $\mathrm{S}_{\mathrm{CO}}(\%)$ & \\
\hline \multirow[t]{4}{*}{$\mathrm{Mn}_{3} \mathrm{O}_{4}$} & 1 & 0.22 & 0.16 & 0.17 & 48.4 & 0.24 \\
\hline & 2 & 0.32 & 0.12 & 0.06 & 67.1 & 0.17 \\
\hline & 3 & 0.21 & 0.07 & 0.02 & 78.3 & 0.12 \\
\hline & 4 & 0.07 & 0.02 & 0.02 & 52.3 & 0.10 \\
\hline \multirow[t]{4}{*}{$3 \% \mathrm{Ce} \mathrm{Mn}_{3} \mathrm{O}_{4}$} & 1 & 3.71 & 1.05 & 0.28 & 78.9 & 1.89 \\
\hline & 2 & 2.09 & 0.56 & 0.07 & 88.8 & 1.39 \\
\hline & 3 & 2.37 & 0.56 & 0.05 & 91.8 & 1.47 \\
\hline & 4 & 2.51 & 0.43 & 0.03 & 93.4 & 1.46 \\
\hline
\end{tabular}

$\mathrm{Mn}_{3} \mathrm{O}_{4}+\mathrm{CH}_{4} \rightarrow 3 \mathrm{MnO}+\mathrm{CO}+2 \mathrm{H}_{2}$,

$\Delta H_{298}^{o}=+196.1 \mathrm{~kJ} \mathrm{~mol}^{-1}$

$7 \mathrm{MnO}+10 \mathrm{CH}_{4} \rightarrow \mathrm{Mn}_{7} \mathrm{C}_{3}+7 \mathrm{CO}+20 \mathrm{H}_{2}$,

$\Delta H_{298}^{0}=+2557.7 \mathrm{~kJ} \mathrm{~mol}^{-1}$

$\mathrm{Mn}_{7} \mathrm{C}_{3}+10 \mathrm{CO}_{2} \rightarrow 7 \mathrm{MnO}+13 \mathrm{CO}$,

$\Delta H_{298}^{o}=-84.4 \mathrm{~kJ} \mathrm{~mol}^{-1}$

Notably, this alternative metal oxide to carbide redox cycle has a theoretical oxygen exchange capacity of $1 \mathrm{~mol}_{\mathrm{O}} \mathrm{mol}_{\mathrm{Mn}}^{-1}$ (Eq. (2)). This is up to four times the theoretical oxygen exchange capacity of pure ceria maintaining its cubic fluorite crystal structure [7,12]. A temporary oxygen exchange capacity of 0.379 was reported by reducing $\mathrm{CeO}_{2}$ to $\mathrm{Ce}_{2} \mathrm{O}_{3}$, however, the $\mathrm{CO}_{2}$ splitting rates decreased rapidly in the first two cycles [11]. The theoretical fuel production yields in this work are unprecedentedly high with $2.86 \mathrm{~mol}_{\mathrm{H} 2} \mathrm{~mol}_{\mathrm{Mn}}^{-1}$ and $1 \mathrm{~mol}_{\mathrm{CO}} \mathrm{mol}_{\mathrm{Mn}}^{-1}$ (Eq. (2)) during methane partial oxidation. In comparison, the highest theoretical $\mathrm{H}_{2}$ and $\mathrm{CO}$ yields from methane partial oxidation reported for cerium dioxide, while maintaining its cubic fluorite crystal structure, are $0.5 \mathrm{~mol}_{\mathrm{H} 2} \mathrm{~mol}_{\mathrm{Ce}}^{-1}$ and $0.25 \mathrm{~mol}_{\mathrm{CO}} \mathrm{mol}_{\mathrm{Ce}}^{-1}$. Similarly, the potential $\mathrm{CO}_{2}$ splitting capacity for the 3\% Ce-doped manganese oxide during the oxidation step is $1.86 \mathrm{~mol}_{\mathrm{CO}} \mathrm{mol}_{\mathrm{Mn}}^{-1}$ (Eq. (3)) and thus more than 7 times higher than that potentially achievable with cerium dioxide $\left(0.25 \mathrm{~mol}_{\mathrm{CO}} \mathrm{mol}_{\mathrm{Ce}}^{-1}\right)$, while maintaining its cubic fluorite crystal structure.

Steinfeld et al. [46] successfully proposed the $\mathrm{Fe}_{3} \mathrm{O}_{4} / \mathrm{Fe}$-based CLR concept achieving a full reduction of the iron oxide from $\mathrm{Fe}_{3} \mathrm{O}_{4}$ to $\mathrm{Fe}$. While this is equivalent to an initial oxygen exchange capacity of $1.33 \mathrm{~mol}_{\mathrm{O}} \mathrm{mol}_{\mathrm{Fe}}^{-1}$, this was limited to the reduction step (from $\mathrm{Fe}_{3} \mathrm{O}_{4}$ to $\mathrm{Fe}$ ), and the re-oxidation (from $\mathrm{Fe}$ to $\mathrm{Fe}_{\mathrm{x}} \mathrm{O}_{\mathrm{y}}$ or possibly $\mathrm{Fe}_{3} \mathrm{O}_{4}$ ) to determine whether the oxygen exchange capacity was reversible and could be sustained for more than one cycle was not investigated. Currently, state-of-the-art iron oxide-based CLRs of methane rely on the $\mathrm{Fe}_{3} \mathrm{O}_{4} / \mathrm{FeO}$ redox pair due to the multi-cycle stability requirements $[47,48]$. The latter yields an oxygen exchange capacity of $0.33 \mathrm{~mol}_{\mathrm{O}}$ $\mathrm{mol}_{\mathrm{Fe}}^{-1}$, which is below the reversible one of $1 \mathrm{~mol}_{\mathrm{O}} \mathrm{mol}_{\mathrm{Mn}}^{-1}$, investigated in our study. To the best of our knowledge, such a high reversible oxygen exchange capacity in CLR has not been previously reported.

Despite this favourable thermodynamics, Fig. 3a shows that the pure $\mathrm{Mn}_{3} \mathrm{O}_{4}$ is unable to perform this oxide-carbide redox cycle (Eqs. (1)-(3)) and only demonstrates small amounts of $\mathrm{H}_{2}$ and $\mathrm{CO}$ during the reduction step $\left(<0.32 \mathrm{~mol}_{\mathrm{H} 2} \mathrm{~mol}_{\mathrm{Mn}}^{-1}\right.$ and $\left.0.16 \mathrm{~mol}_{\mathrm{CO}} \mathrm{mol}_{\mathrm{Mn}}^{-1}\right)$, and $\mathrm{CO}$ during oxidation step $\left(<0.24 \mathrm{~mol}_{\mathrm{CO}} \mathrm{mol}_{\mathrm{Mn}}^{-1}\right)$. More specifically, in the first reduction cycle with the pure $\mathrm{Mn}_{3} \mathrm{O}_{4}$, production of a small amount of $\mathrm{CO}$ and $\mathrm{CO}_{2}$ was simultaneously observed after $5 \mathrm{~min}$, while detectable $\mathrm{H}_{2}$ was only measured after $45 \mathrm{~min}$ and accompanied by a distinct increase in $\mathrm{CO}$ production rate. Evolution of $\mathrm{CO}_{2}$ is an undesirable side reaction indicating complete oxidation of methane. In the subsequent reduction cycles, the amount of evolved $\mathrm{CO}_{2}$ decreased rapidly. These reduction profiles suggest that while a certain amount of reduction from $\mathrm{Mn}_{3} \mathrm{O}_{4}$ into $\mathrm{MnO}$ and perhaps from $\mathrm{MnO}$ to $\mathrm{Mn}_{7} \mathrm{C}_{3}$ according to Eqs. (1) and (2) may be occurring, the reaction rates are likely too slow to advance significantly. This was further supported by the $\mathrm{CO}$ evolution profiles during the oxidation steps. A very small and rapidly decreasing yield and production rate of $\mathrm{CO}$ was observed. Overall, these results further corroborate previous studies indicating that, despite its low-cost and earth-abundancy, pure manganese oxide cannot be efficiently employed for either IGS of MPO-driven thermochemical $\mathrm{CO}_{2}$ and $\mathrm{H}_{2} \mathrm{O}$ splitting cycles. In fact, the highest mass-specific $\mathrm{CO}$ production rate measured here with the pure $\mathrm{Mn}_{3} \mathrm{O}_{4}$ was $2.3 \times 10^{-4} \mathrm{~mol}_{\mathrm{CO}} \mathrm{g}^{-1} \mathrm{~min}^{-1}$, and thus $71 \%$ lower than that of the state-of-the-art $\mathrm{CeO}_{2}[12]$, which at the same conditions reaches a $\mathrm{CO}$ production rate of $8 \times 10^{-4} \mathrm{~mol}_{\mathrm{Co}} \mathrm{g}^{-1} \mathrm{~min}^{-1}$.

Notably, incorporation of $3 \%$ cerium ions in the $\mathrm{Mn}_{3} \mathrm{O}_{4}$ matrix drastically enhanced reduction and oxidation kinetics, unlocking this promising metal oxide-carbide redox cycle (Eqs. (2)-(3)). Fig. 3b shows

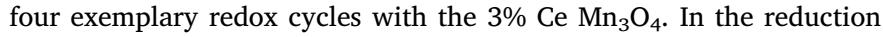
steps, the onset of the $\mathrm{H}_{2}$ and $\mathrm{CO}$ evolution was simultaneous and immediate. The $\mathrm{H}_{2}$ and $\mathrm{CO}$ production rates peaked at $1.6 \times 10^{-1} \mathrm{~mol}_{\mathrm{H} 2}$ $\mathrm{mol}_{\mathrm{Mn}}^{-1} \min ^{-1}$ and $0.5 \times 10^{-1} \mathrm{~mol}_{\mathrm{CO}} \mathrm{mol}_{\mathrm{Mn}}^{-1} \min ^{-1}$, respectively, upon $10 \mathrm{~min}$ into the first reduction step. These rates are more than 20 times higher than that achieved with the pure $\mathrm{Mn}_{3} \mathrm{O}_{4}$. After $35 \mathrm{~min}$ of the first reduction step, the production rates entered a tailing stage, stabilizing at $0.3 \times 10^{-1} \mathrm{~mol}_{\mathrm{H} 2} \mathrm{~mol}_{\mathrm{Mn}}^{-1} \mathrm{~min}^{-1}$ and $0.04 \times 10^{-1} \mathrm{~mol}_{\mathrm{CO}} \mathrm{mol}_{\mathrm{Mn}}^{-1}$ $\min ^{-1}$, respectively. The slight increasing tail of $\mathrm{H}_{2}$ production during the reduction steps (Fig. 3b) is attributed to an increased selectivity toward methane partial oxidation to $\mathrm{H}_{2}$ and $\mathrm{CO}$ over full oxidation to $\mathrm{H}_{2} \mathrm{O}$ and $\mathrm{CO}_{2}$ with increasing reduction time (Table 1 ). This is possibly caused by the decline in oxygen partial pressure during reduction from the metal oxide to metal carbide. Another possible mechanism is methane cracking to carbon and $\mathrm{H}_{2}$. The latter may also be facilitated by the lower oxygen content with the progress of the reduction step and may lead to an increase in $\mathrm{H}_{2}$ production rate. In fact, a certain fraction of methane cracking is confirmed by the carbon deposits observed on the metal carbides by TGA and TEM (Fig. 4c and f). The increasing tail of $\mathrm{CO}$ production rates during the oxidation steps is possibly attributed by the increase of oxygen diffusion rates at the porous domains after the carbon contents are reacted. Over the last 3 reduction steps, the peak rates decreased, while the tail production rates were quite stable resulting in an average of $0.22 \pm 0.01 \times 10^{-1} \mathrm{~mol}_{\mathrm{H} 2} \mathrm{~mol}_{\mathrm{Mn}}^{-1} \mathrm{~min}^{-1}$ and $0.05 \pm 0.008 \times 10^{-1} \mathrm{~mol}_{\mathrm{CO}} \mathrm{mol}_{\mathrm{Mn}}^{-1} \mathrm{~min}^{-1}$, respectively. Furthermore, non-negligible production of $\mathrm{CO}_{2}$ was only observed in the first cycle (Fig. A6). The high $\mathrm{CO} / \mathrm{CO}_{2}$ production ratios show an inverse scenario to that observed for the pure $\mathrm{Mn}_{3} \mathrm{O}_{4}$. As summarized in Fig. A6, increasing $\mathrm{H}_{2}$ tail production rates accompanied by a fast decline in $\mathrm{CO}_{2}$ evolution rates were observed over the 4 redox cycles, indicating an increased selectivity for methane partial over full oxidation (Table 1). Neglecting the first cycle, the average $\mathrm{H}_{2}$ and $\mathrm{CO}$ yields were $2.32 \pm 0.21 \mathrm{~mol}_{\mathrm{H} 2} \mathrm{~mol}_{\mathrm{Mn}}^{-1}$ and $0.52 \pm 0.07 \mathrm{~mol}_{\mathrm{CO}} \mathrm{mol}_{\mathrm{Mn}}^{-1}$, and thus comparable to those $\left(2.86 \mathrm{~mol}_{\mathrm{H} 2} \mathrm{~mol}_{\mathrm{Mn}}^{-1}\right.$ and $\left.1 \mathrm{~mol}_{\mathrm{CO}} \mathrm{mol}_{\mathrm{Mn}}^{-1}\right)$ expected for the complete metal oxide to carbide reaction (Eq. (2)). 

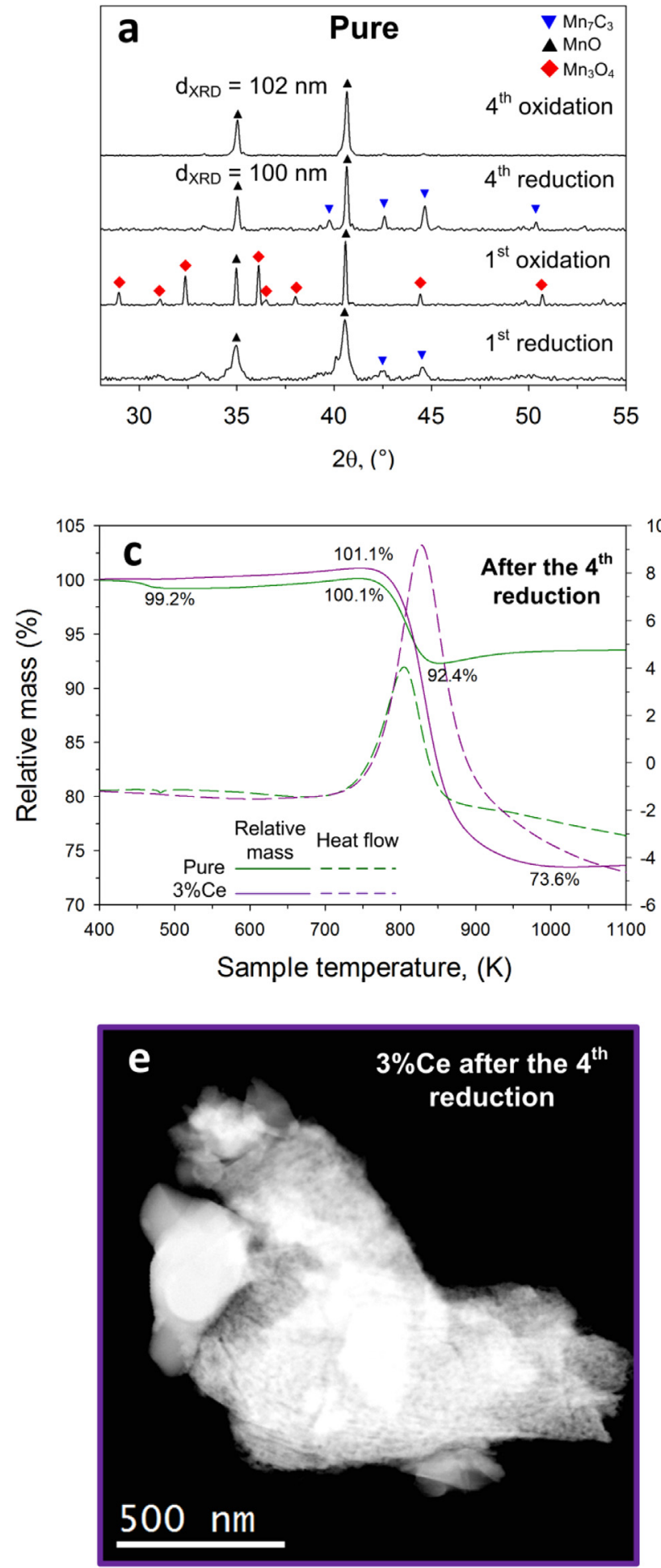
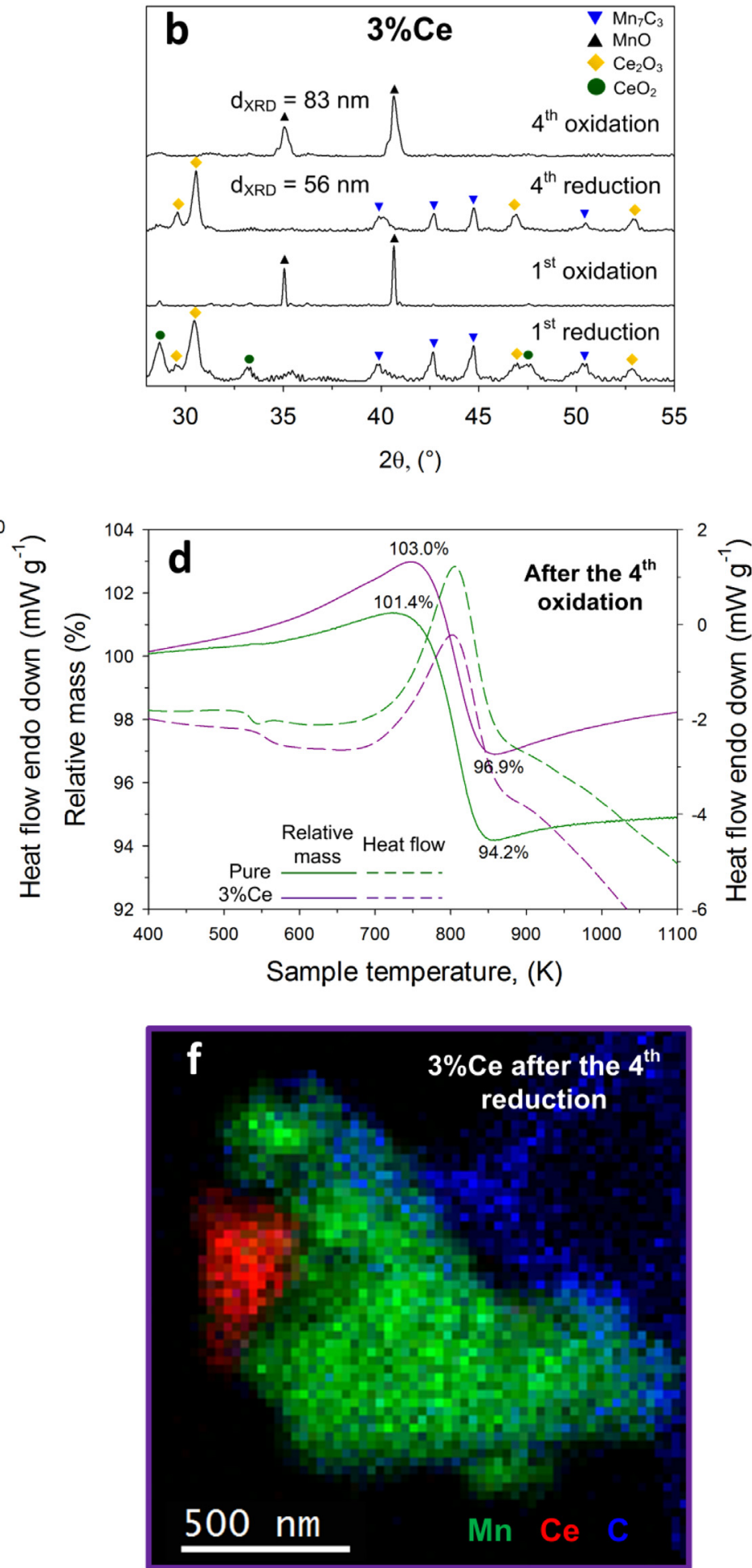

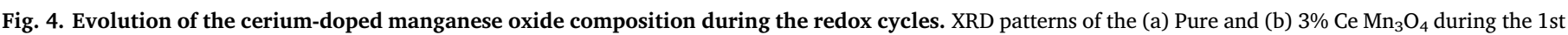

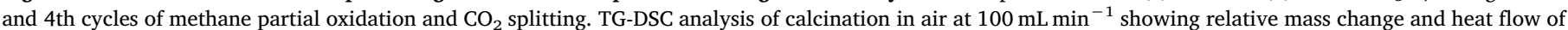

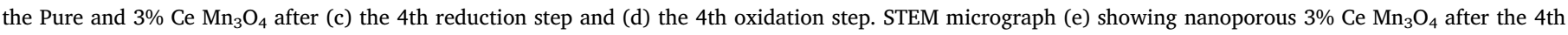
reduction step and its associated elemental mapping (f) showing segregated carbon-rich Mn domains and carbon-free Ce domains.

The $\mathrm{CO}_{2}$ splitting kinetics of the reduced Ce-doped manganese oxide showed fast $\mathrm{CO}$ evolution profiles with sharp initial peaks and sustained tail rates. While the peak $\mathrm{CO}$ production rate decreased from $0.7 \times 10^{-1}$ to $0.5 \times 10^{-1} \mathrm{~mol}_{\mathrm{CO}} \mathrm{mol}_{\mathrm{Mn} \mathrm{min}}^{-1}$ from the first to the fourth cycle, the tail production rates were quite stable at $0.2 \pm 0.02 \times 10^{-1} \mathrm{~mol}_{\mathrm{CO}} \mathrm{mol}_{\mathrm{Mn}}^{-1} \mathrm{~min}^{-1}$. In line with the reduction steps, these $\mathrm{CO}$ production rates were also more than one order of magnitude higher than that of the pure manganese oxide. The CO yield of $1.89 \mathrm{~mol}_{\mathrm{CO}} \mathrm{mol}_{\mathrm{Mn}}^{-1}$, measured in the first cycle, is in good agreement with the theoretical yield predicted by Eq. (3) $\left(1.86 \mathrm{~mol}_{\mathrm{CO}} \mathrm{mol}_{\mathrm{Mn}}^{-1}\right.$ (ca. $23 \%$ ) of $\mathrm{CO}$ produced from oxidation of $\mathrm{Mn}_{7} \mathrm{C}_{3}$ and $1.43 \mathrm{~mol}_{\mathrm{CO}} \mathrm{mol}_{\mathrm{Mn}}^{-1}$ of $\mathrm{CO}$ produced from $\mathrm{CO}_{2}$ splitting. A further contribution of $0.03 \mathrm{~mol}_{\mathrm{CO}}$ $\mathrm{mol}_{\mathrm{Mn}}^{-1}$ is attributed to the reverse Boudouard reaction. This is in line with the thermodynamic analysis (Fig. A2d), which predicts the full 
oxidation of $\mathrm{Mn}_{7} \mathrm{C}_{3}$ to $\mathrm{CO}$ and $\mathrm{MnO}$ during $\mathrm{CO}_{2}$ splitting at above $1150 \mathrm{~K}$. The average $\mathrm{CO}$ yield of $1.44 \pm 0.04 \mathrm{~mol}_{\mathrm{CO}} \mathrm{mol}_{\mathrm{Mn}}^{-1}$ in the last three $\mathrm{CO}_{2}$ splitting steps is comparable to that of $1.86 \mathrm{~mol}_{\mathrm{CO}} \mathrm{mol}_{\mathrm{Mn}}^{-1}$ expected from complete re-oxidation of the carbide to the metal oxide (Eq. (3)). Notably, the mass-specific CO yield of this $3 \% \mathrm{Ce} \mathrm{Mn}_{3} \mathrm{O}_{4}$ was 8 times higher than cerium dioxide [12], while featuring comparable $\mathrm{CO}_{2}$ splitting kinetics.

A first demonstration of the possibility to split $\mathrm{H}_{2} \mathrm{O}$ with the $3 \% \mathrm{Ce}$ $\mathrm{Mn}_{3} \mathrm{O}_{4}$ is shown in Fig. 3c. An approximately $60 \%$ and $70 \%$ higher $\mathrm{H}_{2}$ and $\mathrm{CO}$ peak production rates, respectively, were observed after $7 \mathrm{~min}$ in the first reduction step of the MPO- $\mathrm{H}_{2} \mathrm{O}$ splitting cycles (Fig. 3c), than that of MPO- $\mathrm{CO}_{2}$ splitting cycles (Fig. $3 \mathrm{~b}$ ). This is attributed to the batch-to-batch variation in the specific surface area between the $3 \% \mathrm{Ce}$ doped samples. The inflections observed in the second oxidation step (Fig. 3c) were induced by increasing the steam vapour pressure via increasing the bubbler temperature sequentially from $348 \mathrm{~K}$ to $378 \mathrm{~K}$ during the second $\mathrm{H}_{2} \mathrm{O}$ splitting step. This was done to investigate the effect of the steam concentration on the production rate. The results indicate that the $\mathrm{H}_{2}$ and $\mathrm{CO}$ production rates were increased from $0.06 \mathrm{~mol}_{\mathrm{H} 2} \mathrm{~mol}_{\mathrm{Mn}}^{-1} \mathrm{~min}^{-1}$ to $0.12 \mathrm{~mol}_{\mathrm{H} 2} \mathrm{~mol}_{\mathrm{Mn}}^{-1} \mathrm{~min}^{-1}$ and $0.03 \mathrm{~mol}_{\mathrm{CO}}$ $\mathrm{mol}_{\mathrm{Mn}}^{-1} \mathrm{~min}^{-1}$ to $0.04 \mathrm{~mol}_{\mathrm{CO}} \mathrm{mol}_{\mathrm{Mn}}^{-1} \mathrm{~min}^{-1}$, respectively, by increasing the steam vapour pressure from $0.38 \mathrm{~atm}$ to $1 \mathrm{~atm}$.

To understand the role of the cerium ions in enhancing the redox kinetics and overall thermochemical performance of manganese oxide, the structural properties of the pure and $3 \% \mathrm{Ce} \mathrm{Mn}_{3} \mathrm{O}_{4}$ were mapped along the four two-step cycles. The evolution of the XRD patterns reveals that while presenting the same crystal phase, particle size and nanoscale morphology, these two materials have very distinct redox behaviours (Fig. 4a, b). As suggested by the $\mathrm{H}_{2}$ and $\mathrm{CO}$ evolution profiles (Fig. 3a), the quantitative XRD analysis confirms that the pure $\mathrm{Mn}_{3} \mathrm{O}_{4}$ fails to complete its reduction to metal carbide. Upon the first reduction step only $14 \mathrm{wt} \%$ of $\mathrm{Mn}_{7} \mathrm{C}_{3}$ is formed, while the residual $86 \mathrm{wt} \%$ is slightly reduced to $\mathrm{MnO}$. During the first $\mathrm{CO}_{2}$ splitting step, this $\mathrm{Mn}_{7} \mathrm{C}_{3}-\mathrm{MnO}$ composite is partially re-oxidized to $32 \mathrm{wt} \% \mathrm{Mn}_{3} \mathrm{O}_{4}$ and $68 \mathrm{wt} \% \mathrm{MnO}$. However, after the fourth $\mathrm{CO}_{2}$ splitting step, only $\mathrm{MnO}$ is present with no $\mathrm{Mn}_{3} \mathrm{O}_{4}$ formed. This indicates that while initially there is some cycling between $\mathrm{Mn}_{3} \mathrm{O}_{4}$ and $\mathrm{MnO}$, this path is rapidly deactivated during the first few cycles. The deactivation of this path is attributed to the essential role of the nanoparticle surface for the $\mathrm{Mn}_{3} \mathrm{O}_{4}-\mathrm{MnO}$ redox cycle. As soon as the high specific surface area is lost due to sintering, the oxygen ions in the $\mathrm{MnO}$ lattice do not have enough mobility to re-oxidize it to $\mathrm{Mn}_{3} \mathrm{O}_{4}$. Furthermore, while this is the first demonstration of thermochemical syngas production with pure manganese oxide, the reduction from $\mathrm{Mn}_{3} \mathrm{O}_{4}$ to $\mathrm{MnO}$ (Eq. (1)) has an oxygen exchange stoichiometry of only $0.33 \mathrm{~mol}_{\mathrm{O}} \mathrm{mol}_{\mathrm{Mn}}^{-1}$, and thus is not significantly higher than that of cerium dioxide $\left(0.25 \mathrm{~mol}_{\mathrm{O}} \mathrm{mol}_{\mathrm{Ce}}^{-1}\right)$, while maintaining its cubic fluorite crystal structure. Here, we propose that the small amount of $\mathrm{H}_{2}$ and $\mathrm{CO}$ evolved during the pure manganese oxide redox cycles arise mostly from the $\mathrm{MnO}$ to carbide pathway (Eqs. (2) and (3)). However, the poor mobility of the oxygen ions in the manganese oxide lattice limits the carbide formation to a small surface fraction, thus not allowing to attain the thermodynamic equilibrium (Fig. A2c).

In stark contrast to the pure $\mathrm{Mn}_{3} \mathrm{O}_{4}$, upon the first reduction step, the XRD spectrum of the $3 \% \mathrm{Ce} \mathrm{Mn}_{3} \mathrm{O}_{4}$ reveals the presence of only $\mathrm{Mn}_{7} \mathrm{C}_{3}$ with no trace of $\mathrm{MnO}$ or other manganese oxides (Fig. 4b). A small fraction of ca. $3-5 \mathrm{wt} \% \mathrm{CeO}_{2}$ and $\mathrm{Ce}_{2} \mathrm{O}_{3}$ was also observable in the XRD patterns, indicating exsolution of the cerium from the manganese carbide phase. After the first $\mathrm{CO}_{2}$ splitting step, the manganese carbide was completely oxidized to $\mathrm{MnO}$ with no trace of segregated cerium oxides indicating its re-incorporation into the manganese oxide lattice. Notably, a high extent of the reduction and oxidation was observed also in the fourth cycle (Fig. 4b), and explains the very high $\mathrm{H}_{2}$ and $\mathrm{CO}$ yields measured also during the last three redox cycles (Fig. $3 \mathrm{~b}$ ). The shoulders in the $\mathrm{MnO}$ spectra are tentatively attributed to bimodal crystal size distribution [49], due to cyclic redox reactions as there are no other $\mathrm{Mn}_{7} \mathrm{C}_{3}$ peaks visible. The thermodynamic feasibility of these results was assessed by comparing the Gibbs free energy of formation of possible reduction and oxidation reactions against the reaction temperature. The Ellingham diagram for the reduction (Fig. A2a) shows spontaneous conversion of $\mathrm{Mn}_{3} \mathrm{O}_{4}$ into $\mathrm{MnO}$ under methane-rich environments. When $\mathrm{Mn}_{3} \mathrm{O}_{4}$ is completely consumed, $\mathrm{MnO}$ is spontaneously converted into $\mathrm{Mn}_{7} \mathrm{C}_{3}$ at temperatures above $1150 \mathrm{~K}$ (Eq. (2)). For the re-oxidation by $\mathrm{CO}_{2}$ splitting (Fig. A2b), conversion from $\mathrm{Mn}_{7} \mathrm{C}_{3}$ to $\mathrm{MnO}$ (Eq. (3)) is spontaneous, but further conversion from $\mathrm{MnO}$ to $\mathrm{Mn}_{3} \mathrm{O}_{4}$ is not thermodynamically favourable. Upon the first cycle starting from $\mathrm{Mn}_{3} \mathrm{O}_{4}$, this leads to the observed reversible $\mathrm{MnO}-\mathrm{Mn}_{7} \mathrm{C}_{3}$ cycling described in Eqs. (2) and (3). As a result, the $\mathrm{MnO}$ to $\mathrm{Mn}_{7} \mathrm{C}_{3}$ redox cycle is thermodynamically reversible and followed closely the dictated stoichiometry in Eqs. (2) and (3). The unsatisfactory attempts to cycle the pure manganese oxides are attributed to kinetics constraints in line with the poor oxygen mobility in manganese oxides [50,51].

To verify the amount of manganese carbide formed, the pure and $3 \%$ Ce doped samples were analysed by thermogravimetric differential scanning calorimetry (TG-DSC) under calcination in air at $100 \mathrm{~mL} \mathrm{~min}^{-1}$. Fig. $4 \mathrm{c}$ shows the relative mass change and heat flow during air calcination of the pure and $3 \% \mathrm{Ce} \mathrm{Mn}_{3} \mathrm{O}_{4}$ after the fourth reduction step. Upon calcination in air a main $\mathrm{Mn}_{2} \mathrm{O}_{3}$ phase was detected for both the $3 \% \mathrm{Ce}$ and pure $\mathrm{Mn}_{3} \mathrm{O}_{4}$ samples (Fig. A4). Formation of $\mathrm{Mn}_{2} \mathrm{O}_{3}$ is in line with previous results obtained by calcination of nanostructured manganese oxide in air [24]. Most importantly, a mass loss was observed for both materials with increasing temperature from 800 to $870 \mathrm{~K}$. This is in contrast to the expected mass gain due to oxidation from $\mathrm{Mn}_{7} \mathrm{C}_{3}$ or $\mathrm{MnO}$ to $\mathrm{Mn}_{2} \mathrm{O}_{3}$, which would lead to mass gains for the pure and $3 \% \mathrm{Ce} \mathrm{Mn}_{3} \mathrm{O}_{4}$ samples, respectively. This mass loss (Fig. 4c) is attributed to the combustion of carbon deposits formed on the nanoparticle surface via methane cracking. An estimate of the mass balance based on the XRD compositions and gravimetric variations suggests that upon the fourth reduction the pure manganese oxide samples consisted of $17 \mathrm{wt} \% \mathrm{Mn}_{7} \mathrm{C}_{3}, 63 \mathrm{wt} \% \mathrm{MnO}$ and $20 \mathrm{wt} \%$ carbon deposits. In contrast, the reduced $3 \% \mathrm{Ce} \mathrm{Mn}_{3} \mathrm{O}_{4}$ consisted of $58 \mathrm{wt} \%$ $\mathrm{Mn}_{7} \mathrm{C}_{3}$ and ca. $42 \mathrm{wt} \%$ carbon deposits. The TG-DSC analysis of the re-

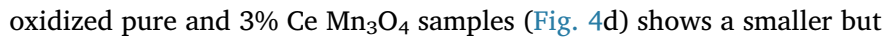
noticeable mass loss of $8 \%$ and $3 \%$, respectively, indicating that after $90 \mathrm{~min}$ in the oxidation cycle there are still some small amounts of carbon deposit (12-15 wt\%). The initial mass gain is attributed to the oxidation of $\mathrm{MnO}$ to higher valence states (first $\mathrm{Mn}_{3} \mathrm{O}_{4}$ and then $\mathrm{Mn}_{2} \mathrm{O}_{3}$ ) before the on-set (ca. $800-870 \mathrm{~K}$ ) of the carbon deposits oxidation to $\mathrm{CO}_{2}$. The latter mass loss overshadows the $11.3 \%$ increase in mass expected for oxidation of the $\mathrm{MnO}$ to the final $\mathrm{Mn}_{2} \mathrm{O}_{3}$, which was detected by XRD in the calcined samples (Fig. A4). Similar amount of methane cracking and carbon deposit have also been reported for the benchmark cerium dioxide in thermochemical $\mathrm{CO}_{2}$ and $\mathrm{H}_{2} \mathrm{O}$ splitting cycles with MPO reduction $[6,52,53]$. While carbon formation by methane cracking decreases the amount of $\mathrm{CO}$ produced in the reduction step, the $\mathrm{CO}$ deficit can be recovered in the oxidation step during $\mathrm{CO}_{2}$ splitting by the reverse Boudouard reaction. Minimizing carbon formation and deposition can be pursued by optimizing the methane concentration, reaction temperature and cycle step time [5].

Electron microscope analysis of the reduced $3 \% \mathrm{Ce} \mathrm{Mn}_{3} \mathrm{O}_{4}$ particles provides some further insights on the role of the cerium ions and the redox mechanism of these composites. After the fourth reduction step,

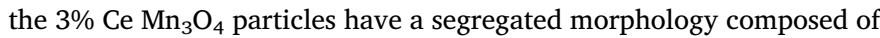
mostly nanoporous Mn-rich particles and some dense Ce domains (Fig. 4e, f). The nanoporous domains are also rich in carbon, while the Ce domains are carbon free. These structures correspond well to the segregated manganese carbide and cerium dioxide crystal phases observed by XRD. Some segregated carbon is also identified outside of the Mn-containing particles. In line with the TGA analysis (Fig. 4c), this is attributed to the carbon deposits formed via methane cracking. It is hypothesised that the cyclic migration of cerium ions in and out of the manganese domains results in a cyclic contraction and expansion of the 

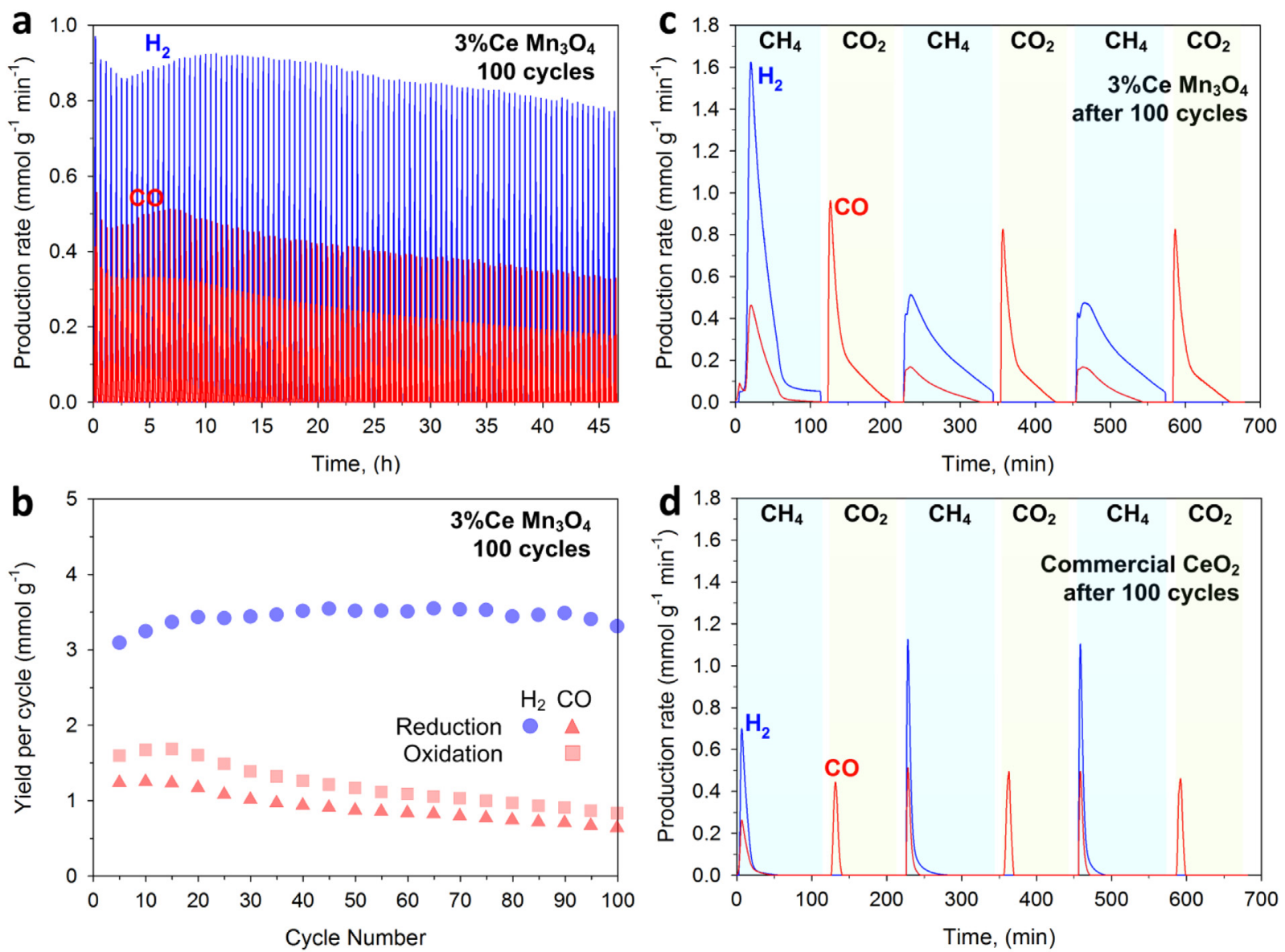

Fig. 5. Investigation of the mid-term $\mathrm{CO}_{2}$ splitting kinetics and mid-term stability over consecutive 100 redox cycles. (a) $\mathrm{H}_{2}$ and $\mathrm{CO}$ production rates of the $3 \% \mathrm{Ce} \mathrm{Mn}_{3} \mathrm{O}_{4}$ during 100 isothermal cycles of methane partial oxidation and $\mathrm{CO}_{2}$ splitting and its (b) $\mathrm{H}_{2}$ and $\mathrm{CO}$ yields in every 5th cycle. $\mathrm{H}_{2}$ and $\mathrm{CO}$ production rates

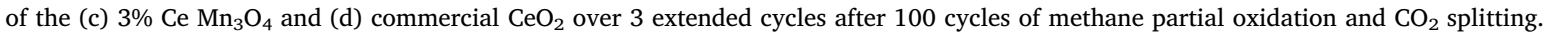

crystal structure, which possibly results in a nanoporous morphology. The latter has extensive grain boundary and defects available for oxygen and reactant diffusion during the reduction and oxidation steps. This is supported by the strong $48 \%$ variation in crystal size of the $3 \%$ Ce $\mathrm{Mn}_{3} \mathrm{O}_{4}$ during the fourth cycle (Fig. 4b) from $56 \mathrm{~nm}$ of the reduction to $83 \mathrm{~nm}$ of the oxidation steps. In comparison, the crystal size of the pure $\mathrm{Mn}_{3} \mathrm{O}_{4}$ varied only by ca. $2 \%$ from $100 \mathrm{~nm}$ to $102 \mathrm{~nm}$ between the reduction and oxidation steps (Fig. 4a). After four redox cycles, the BET analysis revealed a specific surface area of $28 \pm 2 \mathrm{~m}^{2} \mathrm{~g}^{-1}$ and $36 \pm 2 \mathrm{~m}^{2} \mathrm{~g}^{-1}$ for the pure $\mathrm{Mn}_{3} \mathrm{O}_{4}$ and $3 \% \mathrm{Ce} \mathrm{Mn}_{3} \mathrm{O}_{4}$, respectively, indicating a $75-85 \%$ drop with respect to the ones of the as-prepared samples of $117 \pm 10 \mathrm{~m}^{2} \mathrm{~g}^{-1}$ and $169 \pm 37 \mathrm{~m}^{2} \mathrm{~g}^{-1}$, respectively. This is in agreement with previous literatures reporting a drop in specific surface area after redox cycles with ceria [12,18,54,55].

To evaluate the thermochemical stability of this material, the $\mathrm{CO}_{2}$

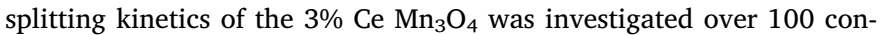
tinuous redox cycles with MPO-driven reduction. A comparative experiment was conducted with cerium dioxide to provide reference values for the overall material performance (Fig. A7). Minimization of methane cracking was achieved by decreasing the reduction and oxidation step times from 90 and 75 min (Fig. 3) to 6 and $12 \mathrm{~min}$. Fig. 5a shows the $\mathrm{H}_{2}$ and $\mathrm{CO}$ evolution rates for the $3 \% \mathrm{Ce} \mathrm{Mn}_{3} \mathrm{O}_{4}$ over these 100 redox cycles. After some initial oscillations and decline in peak $\mathrm{CO}$ production rate for both the reduction and oxidation step, the stepyields stabilized from the 50th cycle onward with an average yield of $3.5 \pm 0.07 \times 10^{-3} \mathrm{~mol}_{\mathrm{H} 2} \mathrm{~g}^{-1}, 0.8 \pm 0.08 \times 10^{-3} \mathrm{~mol}_{\mathrm{CO}} \mathrm{g}^{-1}$, and $1 \pm 0.09 \times 10^{-3} \mathrm{~mol}_{\mathrm{CO}} \mathrm{g}^{-1}$ during methane partial oxidation and $\mathrm{CO}_{2}$ splitting, respectively (Fig. 5b). The initial decrease in the peak rates for methane partial oxidation and $\mathrm{CO}_{2}$ splitting is attributed to the sintering of the nanoparticles, which decreases the available surface area slowing the reduction and oxidation kinetics. This initial surface area decrease is comparable to the behaviour observed with the nanostructured $\mathrm{Mn}_{3} \mathrm{O}_{4}$. However, the impact on the $\mathrm{H}_{2}$ and $\mathrm{CO}$ yield is significantly smaller as the noteworthy bulk-diffusivity of the oxygen ions in both the $3 \% \mathrm{Ce} \mathrm{Mn}_{3} \mathrm{O}_{4}$ and $\mathrm{CeO}_{2}$ keeps driving the redox reactions toward the thermodynamic equilibrium. The slight decline in performance can likely be mitigated by optimisation of the operating mode in a fluidised bed reactor or through the inclusion of a compatible secondary phase, as discussed in previous works [56,57].

Overall, the cerium-doped manganese oxide achieved $75 \%$ higher $\mathrm{H}_{2}$ and $25 \%$ higher $\mathrm{CO}$ yields during the methane partial oxidation step and comparable yields during the $\mathrm{CO}_{2}$ splitting step than the commercial $\mathrm{CeO}_{2}$. The $\mathrm{H}_{2}$ and $\mathrm{CO}$ production rates during the redox steps were comparable to those of $\mathrm{CeO}_{2}$, which is the current benchmark material for fast redox reaction kinetics in thermochemical redox cycles. Table 2 reports a comparative summary of the cyclic performance

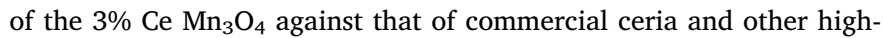
performing materials reported for thermochemical $\mathrm{CO}_{2}$ or $\mathrm{H}_{2} \mathrm{O}$ splitting with inert gas and MPO-driven reductions. It should be noted that MPOdriven reduction is expected to lead to higher syngas yields, due to its capability to induce higher reduction of the material than inert gas reduction. Notably, mass-specific $\mathrm{CO}$ production capacity achieved here for $\mathrm{CO}_{2}$ splitting is $17.72 \mathrm{mmol}_{\mathrm{CO}} \mathrm{g}^{-1}$. This mass-specific $\mathrm{CO}$ production capacity is significantly higher (Table 2) than that reported in other recent studies (e.g. $>10$ times that of recently reported $\mathrm{La}_{0.6} \mathrm{Ca}_{0.4} \mathrm{MnO}_{3}$ [58]), and is attributed to the extraordinary reversible

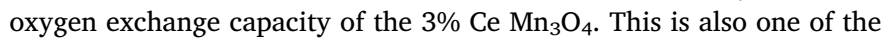
highest $\mathrm{CO}$ production capacities from $\mathrm{CO}_{2}$ splitting so far reported 
Table 2

Comparison of syngas production in two-step thermochemical redox cycles. ${ }^{\text {a }}$

\begin{tabular}{|c|c|c|c|c|c|c|c|c|c|c|}
\hline \multirow[t]{2}{*}{ Material } & \multirow[t]{2}{*}{ Process } & \multirow[t]{2}{*}{$t_{c}(h)$} & \multirow[t]{2}{*}{$\mathrm{N}_{\mathrm{c}}(\#)$} & \multicolumn{3}{|c|}{ Reduction } & \multicolumn{3}{|c|}{ Oxidation } & \multirow[t]{2}{*}{ Ref. } \\
\hline & & & & $\mathrm{T}_{\mathrm{R}}(\mathrm{K})$ & $\begin{array}{l}Y_{\mathrm{H} 2} \\
\left(10^{-}\right.\end{array}$ & ${ }_{1} \mathrm{Y}_{\mathrm{CO}}$ & $\mathrm{T}_{\mathrm{O}}(\mathrm{K})$ & $\begin{array}{l}Y_{\mathrm{H} 2} \\
\left(10^{-3}\right.\end{array}$ & $\mathrm{Y}_{\mathrm{CO}}$ & \\
\hline $3 \% \mathrm{Ce} \mathrm{Mn}_{3} \mathrm{O}_{4}$ & MPO-CDS & 11.7 & 4 & 1173 & 28.6 & 6.39 & 1173 & - & 17.7 & This work \\
\hline $3 \% \mathrm{Ce} \mathrm{Mn}_{3} \mathrm{O}_{4}$ & MPO-WS & 2 & 2 & 1173 & 37.8 & 11.3 & 1173 & 11.2 & 3.63 & This work \\
\hline $3 \% \mathrm{Ce} \mathrm{Mn}_{3} \mathrm{O}_{4}$ & MPO-CDS & 46.7 & 100 & 1173 & 3.44 & 0.90 & 1173 & - & 1.30 & This work \\
\hline $\mathrm{CeO}_{2}$ & MPO-CDS & 46.7 & 100 & 1173 & 1.97 & 0.72 & 1173 & - & 1.55 & This work \\
\hline $\mathrm{Ce}_{0.8} \mathrm{Zr}_{0.2} \mathrm{O}_{2}$ & MPO-WS & $>2.7$ & 1 & 973 & 1.29 & 0.62 & 773 & 0.84 & - & [59] \\
\hline $\mathrm{Ce}_{0.7} \mathrm{Fe}_{0.3} \mathrm{O}_{3}$ & MPO-WS & $>6.3$ & 10 & 1123 & 1.19 & 0.63 & 973 & 1.02 & - & {$[60]$} \\
\hline $\mathrm{CeO}_{2} / \mathrm{SiC}$ & MPO-WS & 0.7 & 3 & 1273 & 1.75 & 0.43 & 1273 & 1.22 & - & [11] \\
\hline $\mathrm{LaFeO}_{3}$ & MPO-WS & $>27$ & 30 & 1073 & 2.00 & 0.27 & 1073 & 3.37 & - & {$[61]$} \\
\hline $\mathrm{LaFe}_{0.9} \mathrm{Ni}_{0.1} \mathrm{O}_{3}$ & MPO-WS & - & 10 & 1123 & - & - & 1123 & 6.69 & - & {$[62]$} \\
\hline $\mathrm{Fe}_{3} \mathrm{O}_{4}$ & MPO-WS & 15.5 & 6 & 1223 & 7.09 & 3.55 & 1123 & 5.25 & - & [47] \\
\hline $\mathrm{CeO}_{2}$ & IGS-WS & 166.7 & 500 & 1773 & - & - & 1073 & 0.61 & - & [1] \\
\hline $\mathrm{CeO}_{2}$ & IGS-WS + CDS & $>8$ & 10 & 1700 & - & - & 1100 & 0.09 & 0.04 & {$[63]$} \\
\hline $\mathrm{Sr}_{0.6} \mathrm{La}_{0.4} \mathrm{Mn}_{0.6} \mathrm{Al}_{0.4} \mathrm{O}_{3}$ & IGS-CDS & 40 & 80 & 1623 & - & - & 1273 & - & 0.14 & [17] \\
\hline $\mathrm{CoFe}_{2} \mathrm{O}_{4} / \mathrm{Al}_{2} \mathrm{O}_{3}$ & IGS-WS & 4.6 & 3 & 1623 & - & - & 1623 & 0.10 & - & [14] \\
\hline $\mathrm{La}_{0.6} \mathrm{Ca}_{0.4} \mathrm{MnO}_{3}$ & RWGS & 3.3 & 5 & 823 & - & - & 823 & - & 1.24 & {$[58]$} \\
\hline
\end{tabular}

${ }^{\mathrm{a}} \mathrm{t}_{\mathrm{c}}$ : operating time; $\mathrm{N}_{\mathrm{c}}$ : number of cycles; $\mathrm{T}_{\mathrm{R}}$ : reduction temperature; $\mathrm{T}_{\mathrm{O}}$ : oxidation temperature; $\mathrm{Y}_{\mathrm{H} 2}: \mathrm{H}_{2}$ yield; $\mathrm{Y}_{\mathrm{CO}}$ : CO yield; $\mathrm{MPO}$ : methane partial oxidation; CDS: carbon dioxide splitting; WS: water splitting; IGS: inert gas sweeping; RWGS: reverse water gas shift.

with an earth-abundant metal oxide material for thermochemical synthesis of solar fuels.

The long-term stability of the Ce-doped manganese oxide was further investigated in a separate experiment by measuring the residual oxygen exchange capacity after the 100 redox cycles. Fig. $5 \mathrm{c}$ and $\mathrm{d}$ show three MPO-driven reduction and $\mathrm{CO}_{2}$ splitting oxidation cycles for

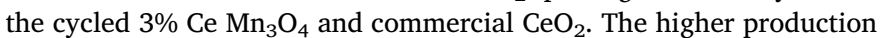
peak rates in the first step of the following 3-cycle investigation (Fig. 5c) are attributed to the longer reaction times, which enable the material to reach its peak production rates. Notably, neglecting the first cycle, the oxygen exchange capacity and $\mathrm{H}_{2}$ and $\mathrm{CO}$ yields of the $3 \% \mathrm{Ce}$ $\mathrm{Mn}_{3} \mathrm{O}_{4}$ was largely unchanged. The latter maintained comparable MPO and $\mathrm{CO}_{2}$ splitting rates and yields to the as-prepared material (Fig. 3). However, it should be noted that the ceria reduction and oxidation terminated significantly earlier in each cycle step than those of the $3 \%$ Ce sample did, and thus a comparison of the overall production rates would require a separate optimisation of the cycling times for both materials independently as observed for the 100 redox cycles. The $3 \%$ Ce revealed up to 7 and 5 times higher $\mathrm{H}_{2}$ and CO yields, respectively, during the reduction steps, and 4-6 times higher $\mathrm{CO}$ yield during the $\mathrm{CO}_{2}$ splitting steps than the commercial $\mathrm{CeO}_{2}$. After 100 redox cycles, the oxygen exchange capacity of the Ce-doped manganese oxide, estimated from the average $\mathrm{CO}$ yield during the MPO steps, was $0.61 \mathrm{~mol}_{\mathrm{O}}$ $\mathrm{mol}_{\mathrm{Mn}}^{-1}$ and thus close to the as-prepared material $\left(0.65 \mathrm{~mol}_{\mathrm{O}} \mathrm{mol}_{\mathrm{Mn}}^{-1}\right)$ despite an $81 \%$ decrease in specific surface area. This is attributed to the drastic improvement in oxygen ion mobility achieved by incorporation of the $\mathrm{Ce}^{4+}$ in the manganese oxide lattice, which may reduce the Mn-O binding energy and also create a microporous morphology.

\section{Conclusions}

In conclusion, doping earth-abundant metal oxides with soluble amounts of high oxygen conductivity materials, such as cerium, may lead to a broadly applicable strategy to improve the redox kinetics and unlock the use of the outstanding oxygen exchange capacity of this broad family of low-cost materials for solar thermochemical fuel synthesis. The cerium-doped manganese oxide, developed here, demonstrates the first metal oxide to carbide redox cycle and efficient use of manganese, one of the most earth-abundant elements, for thermochemical carbon dioxide and water splitting. The incorporation of a fractional amount of cerium ions improved significantly the reduction and oxidation kinetics, resulting in 15 times higher $\mathrm{CO}_{2}$ splitting rates than the undoped manganese oxide, and also 8 times higher $\mathrm{CO}$ yields than cerium oxide. The long-term cyclic performance revealed that this is not a short-lived enhancement and that the cerium ions are able to easily diffuse in and out of the host lattice over hundreds of reduction and oxidation cycles in harsh thermochemical conditions. As an immediate result, these findings provide a novel low-cost earth-abundant material for the large-scale synthesis of solar fuels via efficient thermochemical routes.

\section{Acknowledgements}

This research was performed as part of the Australian Solar Thermal Research Initiative (ASTRI), a project supported by the Australian Government, through the Australian Renewable Energy Agency (ARENA). Financial support from the ARC Discovery Project \#150101939 and the ARC Discovery Early Career Award \#160100569 (A. Tricoli), the ARC Future Fellowship FT140101213 (W. Lipiński), the Australian Government Research Training Program (X. Gao), The Hong Kong Research Grants Council through the Early Career Scheme Project \#25301617 (Y. Zhu) and The Hong Kong Polytechnic University internal Grant 1-ZE6G (Y. Zhu) is gratefully acknowledged. The microscopy analyses were conducted in the Centre of Advanced Microscopy at ANU, the University Research Facility in Materials Characterization and Device Fabrication (UMF) at the Hong Kong Polytechnic University, and Monash Centre for Electron Microscopy (MCEM) at Monash University. X. Gao would like to acknowledge N. Nasiri for the partial support of microscopy image acquisition and T. Tsuzuki for providing TG-DSC instruments. Y. Zhu is grateful to W. Lu for maintaining the JEOL 2100F TEM/STEM at UMF and M. Weyland for optimizing the Titan TEM/STEM at MCEM.

\section{Appendix A. Supplementary material}

Supplementary data associated with this article can be found in the online version at http://dx.doi.org/10.1016/j.nanoen.2018.05.045.

\section{References}

[1] W.C. Chueh, C. Falter, M. Abbott, D. Scipio, P. Furler, S.M. Haile, A. Steinfeld, Highflux solar-driven thermochemical dissociation of $\mathrm{CO}_{2}$ and $\mathrm{H}_{2} \mathrm{O}$ using nonstoichiometric ceria, Science 330 (2010) 1797-1801.

[2] C. Agrafiotis, M. Roeb, C. Sattler, A review on solar thermal syngas production via redox pair-based water/carbon dioxide splitting thermochemical cycles, Renew. Sustain. Energy Rev. 42 (2015) 254-285. 
[3] C.L. Muhich, B.D. Ehrhart, I. Al-Shankiti, B.J. Ward, C.B. Musgrave, A.W. Weimer, A review and perspective of efficient hydrogen generation via solar thermal water splitting, Wires Energy Environ. 5 (2016) 261-287.

[4] A. Steinfeld, Solar thermochemical production of hydrogen - a review, Sol. Energy 78 (2005) 603-615.

[5] C. Agrafiotis, H. von Storch, M. Roeb, C. Sattler, Solar thermal reforming of methane feedstocks for hydrogen and syngas production - a review, Renew. Sustain. Energy Rev. 29 (2014) 656-682.

[6] K. Otsuka, Y. Wang, E. Sunada, I. Yamanaka, Direct partial oxidation of methane to synthesis gas by cerium oxide, J. Catal. 175 (1998) 152-160.

[7] P.T. Krenzke, J.H. Davidson, Thermodynamic analysis of syngas production via the solar thermochemical cerium oxide redox cycle with methane-driven reduction, Energy Fuel 28 (2014) 4088-4095.

[8] R. Bader, L.J. Venstrom, J.H. Davidson, W. Lipiński, Thermodynamic analysis of isothermal redox cycling of ceria for solar fuel production, Energy Fuel 27 (2013) 5533-5544.

[9] P.T. Krenzke, J.R. Fosheim, J.H. Davidson, Solar fuels via chemical-looping reforming, Sol. Energy 156 (2017) 48-72.

[10] P.T. Krenzke, J.R. Fosheim, J.Y. Zheng, J.H. Davidson, Synthesis gas production via the solar partial oxidation of methane-ceria redox cycle: conversion, selectivity, and efficiency, Int. J. Hydrog. Energy 41 (2016) 12799-12811.

[11] M.M. Nair, S. Abanades, Tailoring hybrid nonstoichiometric ceria redox cycle for combined solar methane reforming and thermochemical conversion of $\mathrm{H}_{2} \mathrm{O} / \mathrm{CO}_{2}$, Energy Fuel 30 (2016) 6050-6058.

[12] X. Gao, A. Vidal, A. Bayon, R. Bader, J. Hinkley, W. Lipiński, A. Tricoli, Efficient ceria nanostructures for enhanced solar fuel production via high-temperature thermochemical redox cycles, J. Mater. Chem. A 4 (2016) 9614-9624.

[13] A. Le Gal, S. Abanades, G. Flamant, $\mathrm{CO}_{2}$ and $\mathrm{H}_{2} \mathrm{O}$ splitting for thermochemical production of solar fuels using nonstoichiometric ceria and ceria/zirconia solid solutions, Energy Fuel 25 (2011) 4836-4845.

[14] C.L. Muhich, B.W. Evanko, K.C. Weston, P. Lichty, X. Liang, J. Martinek, C.B. Musgrave, A.W. Weimer, Efficient generation of $\mathrm{H}_{2}$ by splitting water with an isothermal redox cycle, Science 341 (2013) 540-542.

[15] A. Mishra, N. Galinsky, F. He, E.E. Santiso, F. Li, Perovskite-structured $\mathrm{AMn}_{x} \mathrm{~B}_{1-x} \mathrm{O}_{3}$ $(\mathrm{A}=\mathrm{Ca}$ or $\mathrm{Ba} ; \mathrm{B}=\mathrm{Fe}$ or $\mathrm{Ni}$ ) redox catalysts for partial oxidation of methane, Catal. Sci. Technol. 6 (2016) 4535-4544.

[16] H. Wei, Y. Cao, W. Ji, C. Au, Lattice oxygen of $\mathrm{La}_{1}-{ }_{x} \mathrm{Sr}_{x} \mathrm{MO}_{3}(\mathrm{M}=\mathrm{Mn}, \mathrm{Ni})$ and $\mathrm{LaMnO}_{3-\alpha} \mathrm{F}_{\beta}$ perovskite oxides for the partial oxidation of methane to synthesis gas, Catal. Commun. 9 (2008) 2509-2514.

[17] A.H. McDaniel, E.C. Miller, D. Arifin, A. Ambrosini, E.N. Coker, R. O'Hayre, W.C. Chueh, J. Tong, Sr- and Mn-doped $\mathrm{LaAlO}_{3-\delta}$ for solar thermochemical $\mathrm{H}_{2}$ and CO production, Energy Environ. Sci. 6 (2013) 2424-2428.

[18] L.J. Venstrom, N. Petkovich, S. Rudisill, A. Stein, J.H. Davidson, The effects of morphology on the oxidation of ceria by water and carbon dioxide, J. Sol. Energy 134 (2012) 011005.

[19] W.T. Gibbons, L.J. Venstrom, R.M. De Smith, J.H. Davidson, G.S. Jackson, Ceriabased electrospun fibers for renewable fuel production via two-step thermal redox cycles for carbon dioxide splitting, Phys. Chem. Chem. Phys. 16 (2014) 14271-14280.

[20] F. Xie, T.A. Zhang, D. Dreisinger, F. Doyle, A critical review on solvent extraction of rare earths from aqueous solutions, Miner. Eng. 56 (2014) 10-28.

[21] T. Kodama, T. Shimizu, T. Satoh, M. Nakata, K.I. Shimizu, Stepwise production of CO-rich syngas and hydrogen via solar methane reforming by using a Ni(II)-ferrite redox system, Sol. Energy 73 (2002) 363-374.

[22] F. He, Y.G. Wei, H.B. Li, H. Wang, Synthesis gas generation by chemical-looping reforming using Ce-based oxygen carriers modified with $\mathrm{Fe}, \mathrm{Cu}$, and $\mathrm{Mn}$ oxides, Energy Fuel 23 (2009) 2095-2102.

[23] M. Wiechen, M.M. Najafpour, S.I. Allakhverdiev, L. Spiccia, Water oxidation catalysis by manganese oxides: learning from evolution, Energy Environ. Sci. 7 (2014) 2203-2212.

[24] G.Y. Liu, J. Hall, N. Nasiri, T. Gengenbach, L. Spiccia, M.H. Cheah, A. Tricoli, Scalable synthesis of efficient water oxidation catalysts: insights into the activity of flame-made manganese oxide nanocrystals, Chemsuschem 8 (2015) 4162-4171.

[25] F.Y. Cheng, J.A. Shen, B. Peng, Y.D. Pan, Z.L. Tao, J. Chen, Rapid room-temperature synthesis of nanocrystalline spinels as oxygen reduction and evolution electrocatalysts, Nat. Chem. 3 (2011) 79-84.

[26] H. Kaneko, T. Miura, H. Ishihara, S. Taku, T. Yokoyama, H. Nakajima, Y. Tamaura, Reactive ceramics of $\mathrm{CeO}_{2}-\mathrm{MO}_{x}(\mathrm{M}=\mathrm{Mn}, \mathrm{Fe}, \mathrm{Ni}, \mathrm{Cu})$ for $\mathrm{H}_{2}$ generation by two-step water splitting using concentrated solar thermal energy, Energy 32 (2007) 656-663.

[27] T.M. Francis, P.R. Lichty, A.W. Weimer, Manganese oxide dissociation kinetics for the $\mathrm{Mn}_{2} \mathrm{O}_{3}$ thermochemical water-splitting cycle. Part 1: experimental, Chem. Eng. Sci. 65 (2010) 3709-3717.

[28] M. Sturzenegger, J. Ganz, P. Nuesch, T. Schelling, Solar hydrogen from a manganese oxide based thermochemical cycle, J. Phys. IV 9 (1999) 331-335.

[29] P.B. Kreider, H.H. Funke, K. Cuche, M. Schmidt, A. Steinfeld, A.W. Weimer, Manganese oxide based thermochemical hydrogen production cycle, Int. J. Hydrog. Energy 36 (2011) 7028-7037.

[30] A. Bayón, V.A. de la Peña O'Shea, D.P. Serrano, J.M. Coronado, Influence of structural and morphological characteristics on the hydrogen production and sodium recovery in the $\mathrm{NaOH}-\mathrm{MnO}$ thermochemical cycle, Int. J. Hydrog. Energy 38 (2013) 13143-13152.
[31] A. Bayón, V.A. de la Peña O'Shea, J.M. Coronado, D.P. Serrano, Role of the physicochemical properties of hausmannite on the hydrogen production via the $\mathrm{Mn}_{3} \mathrm{O}_{4}-\mathrm{NaOH}$ thermochemical cycle, Int. J. Hydrog. Energy 41 (2016) 113-122.

[32] N. Nasiri, R.H. Bo, F. Wang, L. Fu, A. Tricoli, Ultraporous electron-depleted ZnO nanoparticle networks for highly sensitive portable visible-blind UV photodetectors, Adv. Mater. 27 (2015) 4336-4343.

[33] G. Liu, W.S. Wong, N. Nasiri, A. Tricoli, Ultraporous superhydrophobic gaspermeable nano-layers by scalable solvent-free one-step self-assembly, Nanoscale 8 (2016) 6085-6093.

[34] C.W. Bale, E. Belisle, P. Chartrand, S.A. Decterov, G. Eriksson, K. Hack, I.H. Jung, Y.B. Kang, J. Melancon, A.D. Pelton, C. Robelin, S. Petersen, FactSage thermochemical software and databases - recent developments, Calphad-Comput. Coupling Phase Diagr. Thermochem. 33 (2009) 295-311.

[35] M.D. Allendorf, R.B. Diver, N.P. Siegel, J.E. Miller, Two-step water splitting using mixed-metal ferrites: thermodynamic analysis and characterization of synthesized materials, Energy Fuel 22 (2008) 4115-4124.

[36] C.C. Hu, Y.T. Wu, K.H. Chang, Low-temperature hydrothermal synthesis of $\mathrm{Mn}_{3} \mathrm{O}_{4}$ and $\mathrm{MnOOH}$ single crystals: determinant influence of oxidants, Chem. Mater. 20 (2008) 2890-2894.

[37] P. Zhang, H. Lu, Y. Zhou, L. Zhang, Z. Wu, S. Yang, H. Shi, Q. Zhu, Y. Chen, S. Dai, Mesoporous $\mathrm{MnCeO}_{\mathrm{x}}$ solid solutions for low temperature and selective oxidation of hydrocarbons, Nat. Commun. 6 (2015) 8446.

[38] D.R. Mullins, S.H. Overbury, D.R. Huntley, Electron spectroscopy of single crystal and polycrystalline cerium oxide surfaces, Surf. Sci. 409 (1998) 307-319.

[39] M.C. Biesinger, B.P. Payne, A.P. Grosvenor, L.W.M. Lau, A.R. Gerson, R.S. Smart, Resolving surface chemical states in XPS analysis of first row transition metals, oxides and hydroxides: Cr, Mn, Fe, Co and Ni, Appl. Surf. Sci. 257 (2011) 2717-2730.

[40] A. Serrano-Lotina, L. Daza, Influence of the operating parameters over dry reforming of methane to syngas, Int. J. Hydrog. Energy 39 (2014) 4089-4094.

[41] K. Zhao, F. He, Z. Huang, A.Q. Zheng, H.B. Li, Z.L. Zhao, $\mathrm{La}_{1-x} \mathrm{Sr}_{x} \mathrm{FeO}_{3}$ perovskites as oxygen carriers for the partial oxidation of methane to syngas, Chin. J. Catal. 35 (2014) 1196-1205.

[42] A. Serrano-Lotina, L. Daza, Long-term stability test of Ni-based catalyst in carbon dioxide reforming of methane, Appl. Catal. A-Gen. 474 (2014) 107-113.

[43] N. Anacleto, O. Ostrovski, S. Ganguly, Reduction of manganese oxides by methanecontaining gas, ISIJ Int. 44 (2004) 1480-1487.

[44] O. Ostrovski, G.Q. Zhang, Reduction and carburization of metal oxides by methanecontaining gas, AlChE J. 52 (2006) 300-310.

[45] C.H. Eom, D.J. Min, Kinetics of the formation reaction of manganese carbide under various gases, Met. Mater. Int. 22 (2016) 129-135.

[46] A. Steinfeld, P. Kuhn, J. Karni, High-temperature solar thermochemistry - production of iron and synthesis gas by $\mathrm{Fe}_{3} \mathrm{O}_{4}$-reduction with methane, Energy 18 (1993) 239-249.

[47] C.Q. Lu, K.Z. Li, H. Wang, X. Zhu, Y.G. Wei, M. Zheng, C.H. Zeng, Chemical looping reforming of methane using magnetite as oxygen carrier: structure evolution and reduction kinetics, Appl. Energy 211 (2018) 1-14.

[48] K.S. Go, S.R. Son, S.D. Kim, K.S. Kang, C.S. Park, Hydrogen production from twostep steam methane reforming in a fluidized bed reactor, Int. J. Hydrog. Energy 34 (2009) 1301-1309.

[49] T. Rudin, K. Wegner, S.E. Pratsinis, Uniform nanoparticles by flame-assisted spray pyrolysis (FASP) of low cost precursors, J. Nanopart. Res. 13 (2011) 2715-2725.

[50] M. Nolan, J.E. Fearon, G.W. Watson, Oxygen vacancy formation and migration in ceria, Solid State Ion. 177 (2006) 3069-3074.

[51] G. Zhou, P.R. Shah, R.J. Gorte, A study of cerium-manganese mixed oxides for oxidation catalysis, Catal. Lett. 120 (2008) 191-197.

[52] J.T. Jang, K.J. Yoon, J.W. Bae, G.Y. Han, Cyclic production of syngas and hydrogen through methane-reforming and water-splitting by using ceria-zirconia solid solutions in a solar volumetric receiver-reactor, Sol. Energy 109 (2014) 70-81.

[53] H.H. Jeong, J.H. Kwak, G.Y. Han, K.J. Yoon, Stepwise production of syngas and hydrogen through methane reforming and water splitting by using a cerium oxide redox system, Int. J. Hydrog. Energy 36 (2011) 15221-15230.

[54] A.C. Gladen, J.H. Davidson, The morphological stability and fuel production of commercial fibrous ceria particles for solar thermochemical redox cycling, Sol. Energy 139 (2016) 524-532.

[55] C.D. Malonzo, R.M. De Smith, S.G. Rudisill, N.D. Petkovich, J.H. Davidson, A. Stein, Wood-templated $\mathrm{CeO}_{2}$ as active material for thermochemical $\mathrm{CO}$ production, J. Phys. Chem. C 118 (2014) 26172-26181.

[56] A. Shafiefarhood, J.C. Hamill, L.M. Neal, F. Li, Methane partial oxidation using $\mathrm{FeO}_{x} @ \mathrm{La}_{0.8} \mathrm{Sr}_{0.2} \mathrm{FeO}_{3-\delta}$ core-shell catalyst-transient pulse studies, Phys. Chem. Chem. Phys. 17 (2015) 31297-31307.

[57] N.L. Galinsky, A. Shafiefarhood, Y.G. Chen, L. Neal, F.X. Li, Effect of support on redox stability of iron oxide for chemical looping conversion of methane, Appl. Catal. B-Environ. 164 (2015) 371-379.

[58] D. Maiti, B.J. Hare, Y.A. Daza, A.E. Ramos, J.N. Kuhn, V.R. Bhethanabotla, Earth abundant perovskite oxides for low temperature $\mathrm{CO}_{2}$ conversion, Energy Environ. Sci. 11 (2018) 648-659.

[59] K. Otsuka, Y. Wang, M. Nakamura, Direct conversion of methane to synthesis gas through gas-solid reaction using $\mathrm{CeO}_{2}-\mathrm{ZrO}_{2}$ solid solution at moderate temperature, Appl. Catal. A-Gen. 183 (1999) 317-324.

[60] Z. Xing, W. Hua, W. Yonggang, L. Kongzhai, X. Cheng, Hydrogen and syngas production from two-step steam reforming of methane over $\mathrm{CeO}_{2}-\mathrm{Fe}_{2} \mathrm{O}_{3}$ oxygen carrier, 
J. Rare Earth 28 (2010) 907-913.

[61] Y. Zheng, K. Li, H. Wang, D. Tian, Y. Wang, X. Zhu, Y. Wei, M. Zheng, Y. Luo, Designed oxygen carriers from macroporous $\mathrm{LaFeO}_{3}$ supported $\mathrm{CeO}_{2}$ for chemicallooping reforming of methane, Appl. Catal. B-Environ. 202 (2017) 51-63.

[62] Y. Shen, K. Zhao, F. He, H. Li, The structure-reactivity relationships of using threedimensionally ordered macroporous $\mathrm{LaFe}_{1-} \mathrm{Ni}_{x} \mathrm{O}_{3}$ perovskites for chemicallooping steam methane reforming, J. Energy Inst. (2018).
[63] P. Furler, J.R. Scheffe, A. Steinfeld, Syngas production by simultaneous splitting of $\mathrm{H}_{2} \mathrm{O}$ and $\mathrm{CO}_{2}$ via ceria redox reactions in a high-temperature solar reactor, Energy Environ. Sci. 5 (2012) 6098-6103.

[64] R. Bader, W. Lipiński, Solar thermal processing, in: M.J. Blanco, L.R. Santigosa (Eds.), Advances in Concentrating Solar Thermal Research and Technology, Woodhead Publishing Series in Energy, Woodhead Publishing, Amsterdam, 2017, pp. 403-459. 